\title{
Gas-Phase Molecular Structure and Energetics of Anionic Silicates
}

José R. B. Gomes ${ }^{\mathrm{a}, \mathrm{b},{ }^{*}}$, M. Natália D. S. Cordeiro ${ }^{\mathrm{c}}$, Miguel Jorge $\mathrm{e}^{\mathrm{c}, \mathrm{d}^{*}}$

${ }^{a}$ CIQ-UP, Faculdade de Ciências, Universidade do Porto, Rua do Campo Alegre 687, 4169-007

Porto, Portugal

${ }^{b}$ CICECO, Universidade de Aveiro, 3810-193 Aveiro, Portugal

${ }^{c}$ REQUIMTE, Faculdade de Ciências, Universidade do Porto, Rua do Campo Alegre 687, 4169-007

Porto, Portugal

${ }^{d}$ LSRE, Faculdade de Engenharia, Universidade do Porto, Rua Dr. Roberto Frias, s/n, 4200-465

Porto, Portugal

*corresponding authors; emails: jrgomes@ua.pt ; mjorge@fe.up.pt 


\begin{abstract}
The gas-phase stabilities of linear, branched and cyclic silicates made of up to five silicon atoms were studied with density functional theory (DFT). The starting geometries for the DFT calculations at the B3LYP/6-311+G(2d,2p) level of theory were obtained from classical molecular dynamics simulations. We have observed that geometric parameters and charges are mainly affected by the degree of deprotonation. Charges on Si atoms are also influenced by their degree of substitution. The enthalpy of deprotonation of the neutral species was found to decrease with the size of the molecule, while the average deprotonation enthalpy of highly charged compounds increased with molecular size. Furthermore, the formation of rings in highly charged silicates is enthalpically preferred to chain growth. These observations result from two competing effects: the easier distribution of negative charge in silicates with low charge density and the strong intramolecular repulsions present in silicates with high charge density. As a consequence, highly charged silicates in the gas phase tend to be as small and as highly condensed as possible, which is in line with experimental observations from solution NMR.
\end{abstract}




\section{INTRODUCTION}

The chemistry of silica under basic $\mathrm{pH}$ conditions plays a crucial role in geochemical processes (Iler, 1979; Crerar et al., 1981) and in the synthesis of materials such as zeolites (Davis and Lobo, 1992; Auerbach et al. 2003), ceramics (Brinker and Sherer, 1990; Šefč́́k and McCormick, 1997) and periodic mesoporous silicas (Firouzi et al., 1997). A detailed understanding of silicate speciation in alkaline solutions, as well as of the interactions of anionic silicates with other components of the synthesis mixture (such as water, organic solvents, aluminates and molecular or supra-molecular templates) is essential to develop more controlled procedures for the synthesis of these materials. Computational studies can provide important insights into these phenomena, since they are able to probe the system on an atomic and molecular level, yielding information that is not easy to obtain experimentally. Nevertheless, ab initio computational studies of anionic silicates are scarce, and have, for the most part, been restricted to silicic acid monomers and dimers (Moravetski et al., 1996; Xiao and Lasaga, 1996; Rustad et al., 2000; Tossell and Sahai, 2000; Šefč́́k and Goddard III, 2001).

Most of the experimental information we now possess regarding the nature and stability of silicate species in solution has been obtained from ${ }^{29} \mathrm{Si} \mathrm{NMR}$ studies (Harris et al., 1981; Engelhardt and Hoebbel, 1983; Harris and Knight, 1983; Kinrade and Swaddle, 1988; Kinrade and Pole, 1992; Kinrade et al., 1998). These studies point to the existence of a restricted range of stable silicate species in alkaline solutions. By employing ${ }^{29} \mathrm{Si}$-enriched materials, Harris, Knight, Kinrade and coworkers have identified 23 distinct species (Harris et al., 1981; Harris and Knight, 1983; Kinrade and Swaddle, 1988; Knight, 1990; Knight and Kinrade, 2002). Recently, a few more anions have been added to this list (Haouas and Taulelle, 2006). The main conclusion that arises is that silicate species in aqueous alkaline solutions tend to adopt morphologies that are as condensed as possible, 
such as small ring- and cage-like species. Furthermore, the relative abundance of these species, but not their nature, may depend on the components present in the solution (Kinrade and Pole, 1992; Kinrade et al., 1998; Knight and Kinrade, 2002). However, other researchers have suggested the existence of silicate species containing more open structures, resembling fragments of zeolite materials (Kirschhock et al., 1999; Houssin et al. 2003). The presence or absence of these structures in zeolite synthesis solutions has been the subject of heated debate in recent years (Kirschhock et al., 1999; Knight and Kinrade, 2002; Houssin et al. 2003; Knight et al., 2006).

Despite recent advances in experimental techniques, it is still rather difficult, due to the large variety of species present simultaneously in solution and to the high complexity of the chemistry of silicon oxides, to obtain precise information regarding the structures and relative stabilities of silica clusters, as well as energies and mechanisms of possible reactions involving these clusters. To clarify some issues left unanswered by experimental data, computational studies of silicates have been performed. Early theoretical work has focused on small neutral silica clusters as a means to gather information about solid materials (Hill and Sauer, 1994; Teppen et al., 1994). Hill and Sauer (1994) have performed Hartree-Fock (HF) calculations on several zeolite fragments saturated by hydrogen atoms: dimer, linear trimer, cyclic trimer, cyclic tetramer, cyclic pentamer, cyclic hexamer, cubic octamer, hexagonal dodecamer and sodalite cage. The authors then fitted the results of their ab initio calculations in the gas phase to obtain force field parameters for simulating zeolites. Later, Moravetski et al. (1996) reported theoretical ${ }^{29} \mathrm{Si}$ NMR chemical shifts for most of these fragments, as well as for the prismatic hexamer and the tetrahedral tetramer. A systematic study of a large variety of neutral silica clusters using DFT was performed by Pereira et al. (1999a, 1999b) Gas-phase molecular structures, energies, dipole moments and atomic charges were presented. The flexibility of the Si-O-Si angle and the ability to form intramolecular hydrogen bonds were identified as the two main factors controlling the wide variety of observed structures in vacuo. In some cases, general trends in cluster stability matched those observed experimentally. It should 
be noted, however, that clusters with four or more Si atoms were treated only at the local DFT level, due to restrictions in available computer power.

There have been fewer theoretical studies devoted to anionic silicates. Anionic forms of monosilicic acid have been optimized using HF (Kubicki et al, 1995; Moravetski et al., 1996; Tossell and Sahai, 2000; Šefč́́k and Goddard III, 2001), MP2 (Kubicki et al, 1995; Tossell and Sahai, 2000; Šefćík and Goddard III, 2001) and DFT methods (Rustad et al., 2000; Tossell and Sahai, 2000; Šefčík and Goddard III, 2001). Šefćík and Goddard III (2001) used several different computational approaches to calculate the acidity of monosilicic acid and obtained good agreement with experimental values. They concluded that in order to obtain accurate energies, diffuse functions had to be included in the calculations. Xiao and Lasaga (1996) have presented the HF/6-31G* optimized geometry of the singly-deprotonated dimer as part of a study on quartz dissolution. Kubicki et al (1996) calculated the deprotonation energy of a branched tetramer in an attempt to represent the deprotonation of mineral surfaces. The anionic monomer and dimer were studied by Tossell and Sahai (2000), who also looked into the deprotonation energies of the cyclic trimer and the cyclic tetramer. The structure for the single-deprotonated dimer obtained by these authors differed significantly from the one calculated by Xiao and Lasaga (1996) at the same level of theory. More recently, two studies have focused on larger deprotonated silicates (Murashov, 2003; MoraFonz et al., 2005). Murashov (2003) has applied DFT methods to the neutral and singlydeprotonated forms of the monomer, dimer, trimer and branched tetramer. Energies, structures and charges of these species were presented. However, this author was mainly concerned with characterizing bonding around silica surface sites. As such, he concentrated on structures with a high degree of symmetry and did not perform an exhaustive study of different minima on the potential energy surface. Mora-Fonz et al. (2005) have presented the energies of several neutral and anionic silicates, both in the gas phase and in a continuum model solvent. Their objective was to compare relative energies and discuss trends in deprotonation and condensation reactions. 
Unfortunately, the energies presented by Mora-Fonz et al. (2005) have been obtained with a basis set where diffuse functions were absent and, as pointed out by Šefčík and Goddard III (2001) for the monomer, this is essential for obtaining accurate energies. One should expect the errors introduced by the absence of diffuse functions in the calculations to be even higher for larger charged silicates. Therefore, due to the inconsistencies that seem to affect theoretical studies of anionic silicates, it would be important to perform a systematic analysis of the molecular structure and energetics of these compounds.

In this paper, we present results of a comprehensive DFT study of neutral and anionic silicates in the gas phase, ranging from the monomer to the pentamer. Detailed structures, charges and energies are given, and a discussion of the relative stability of these species is presented. Our calculations complement those of Pereira et al. (1999a, 1999b) on neutral silicates, since we employ a much higher level of theory (now possible due to improvements in computer power). We employ a large basis set, augmented by diffuse functions, so as to obtain accurate deprotonation and condensation energies, avoiding the pitfalls of previous theoretical studies on anionic silicates. Trends in gas-phase energies can provide useful insights about complex reactions in solution (Pereira et al., 1999a; Gomes et al., 2003; Camps et al., 2006; Ferraz et al., 2007), but cannot be quantitatively compared to experimental solution chemistry, since solvation effects are not accounted for. In an attempt to circumvent this problem, we have repeated the energy calculations in the presence of a continuum model solvent. In a subsequent publication, we will present results of a more detailed theoretical study of anionic silicates in continuum model solvents, as well as in the presence of explicit water molecules. Results of our DFT calculations have already been used in molecular dynamics simulations of the early stages of periodic mesoporous silica synthesis (Jorge et al., 2007). The present paper is organized as follows: Section 2 gives details of the computational procedures; Section 3 addresses the main results of our study and discusses the gas-phase structures and charges obtained, as well as trends in deprotonation and condensation energies; finally, in 
Section 4 we present some conclusions and outline future work to be undertaken.

\section{COMPUTATIONAL DETAILS}

In the present study, and except where explicitly noted, we have used the hybrid B3LYP method based on the ideas of Becke (1993) and introducing a mixture of Hartree-Fock and DFT exchange, B3 functional together with the LYP correlation functional due to Lee et al. (1998). Other functionals were also tested, but none emerged as a clear and more appropriate choice than B3LYP (additional details are given in the Electronic Annex EA-1). All calculations were performed using the Gaussian03 computational code (Frisch et al. 2004). These DFT calculations were undertaken for a large number of linear, branched and cyclic silicate species, with up to five silicon atoms: monomer, dimer, linear trimer, cyclic trimer, linear tetramer, cyclic tetramer, branched tetramer, cyclic branched tetramer (or substituted cyclic trimer), linear pentamer, double-branched pentamer (or pentamer "cross"). These compounds were studied in their neutral forms and also at several degrees of deprotonation. Even the smallest of these molecules possesses a large number of conformational degrees of freedom, which makes the identification of the true minimum on the potential energy surface (PES) a difficult task. The strategy we have adopted to identify, as much as

possible, the global minimum for each silicate consisted of the following steps: (i) generation of several starting configurations; (ii) optimization of all starting configurations at the B3LYP/6$31 \mathrm{G}(\mathrm{d})$ level of theory; (iii) identification of the most stable structure including confirmation as true minima on the PES by calculation of vibrational frequencies; (iv) re-optimization of the latter and calculation of thermal corrections for $T=298.15 \mathrm{~K}$ (vibrational frequencies) at the B3LYP/6$311+\mathrm{G}(2 \mathrm{~d}, 2 \mathrm{p})$ level of theory.

Ideally, one would want to include as many starting configurations as possible, in order to 
span all of the configurational space. However, limitations in computing power imply that one must be more judicious in our choice of starting configurations. For the simplest silicates, i.e., the monomer $\mathrm{Si}(\mathrm{OH})_{4}$ and the dimer $\mathrm{Si}(\mathrm{OH})_{3}-\mathrm{O}-\mathrm{Si}(\mathrm{OH})_{3}$, several starting configurations were generated by hand for their neutral and anionic forms, some enforcing internal symmetry and some without symmetry. For all these species, point charges on each atom were computed using the CHelpG method (Breneman and Wiberg, 1990).

Due to the high flexibility present in the larger silicates studied here (from the trimers to the pentamers), suitable initial geometries for the DFT calculations were obtained from short classical Molecular Dynamics (MD) simulations of these species. The force field for the MD simulations of these neutral and anionic silicates was built by adopting the intramolecular and Lennard-Jones parameters of Pereira et al. (2002), together with the average value of the CHelpG point charges computed for the monomer and dimer derivatives, as described above. For each of the larger silicates, a 100 ps MD trajectory was generated using the GROMACS software package (Berendsen et al., 1995; Lindahl et al., 2001) with a time step of 1 fs. Ten independent configurations per species were chosen randomly from the simulated trajectory and used as starting points for the DFT calculations. It must be stressed that in some cases, the calculations at the lowest DFT level yielded two or more almost degenerate structures and, in those cases, the calculations at the highest DFT level of theory were extended to those structures in order to be sure which was the most stable. Except where noted, all properties were calculated on the most stable structure using the B3LYP/6$311+\mathrm{G}(2 \mathrm{~d}, 2 \mathrm{p})$ approach. Furthermore, point charges on each atom were computed using the Mulliken (Mulliken, 1995), CHelpG (Breneman and Wiberg, 1990) and NPA (Reed et al., 1985) methods.

After all structures were optimized in the gas phase, additional single point calculations were carried out within a self-consistent reaction field (SCRF) using the default IEF-PCM approach, UA0 radii and relative permittivity to simulate solvation by water. Deprotonation and condensation 
energies were recalculated using the values obtained in the PCM computations in order to include a measure of solvation effects. Furthermore, isotropic magnetic shield tensors were calculated with the gauge including atomic orbitals (GIAO) method. The NMR chemical shifts for ${ }^{29} \mathrm{Si}$ and ${ }^{1} \mathrm{H}$ were calculated with respect to isolated tetramethylsilane (TMS), symmetry $T_{d}$, while those for ${ }^{17} \mathrm{O}$ were calculated with respect to isolated $\mathrm{H}_{2} \mathrm{O}$, symmetry $\mathrm{C}_{2 \mathrm{v}}$. The reference state used for the latter in NMR experiments is usually liquid water, so we have added a correction of $35 \mathrm{ppm}$ to the calculated ${ }^{17} \mathrm{O}$ chemical shifts to account for the difference between water molecules in the liquid and vapor states (Florin and Alei, 1967). Calculated isotropic GIAO magnetic shielding tensors were: ${ }^{29} \mathrm{Si}$, $329.1 \mathrm{ppm},{ }^{1} \mathrm{H}, 31.8 \mathrm{ppm}$ and ${ }^{17} \mathrm{O}, 324.9 \mathrm{ppm}$.

\section{RESULTS}

\subsection{Structures of neutral and anionic silicates}

Views of the optimized structures of all neutral and anionic silicates considered in the present work, as well as selected bond lengths and angles, are shown in Figs. 1 to 5. Tables with bond lengths and bond angles for all these species are given in the Electronic Annex EA-2. In Figs. 1-5 and throughout the remainder of the paper, the different compounds studied are distinguished by the use of the following notation: the neutral monomer, $\operatorname{Si}(\mathrm{OH})_{4}$, as well as a fragment resulting from the condensation of a neutral monomer, is denoted by $\mathrm{SN}$; the ionic monomer, $\left[\mathrm{Si}(\mathrm{OH})_{3} \mathrm{O}\right]^{-}$, or an ionic fragment resulting from the condensation of an ionic monomer, is denoted by SI (not to be confused with the silicon atom, Si). Thus, using this notation, a neutral dimer is labeled as SN2 (two neutral fragments), a single-charged dimer as SNSI and a double-charged dimer with a single charge per Si atom as SI2 (no silicates with more than one charge per fragment were considered). The 
SN2SISN label, for instance, is used for a linear tetramer with a negative charge in one of the central fragments. The "cyc" label refers to a cyclic silicate, e.g. SI3_cyc for the triple-charged cyclic trimer. Finally, parentheses are used for branched species, wherein, for example, (SN)-3SN means that three $\mathrm{H}$ atoms in a central neutral monomer were condensed with three SN units.

With regard to atom types, these will be denoted as follows: $\mathrm{Si}$ is a silicon atom, $\mathrm{Oh}$ is an oxygen atom in a hydroxyl group, $\mathrm{Oc}$ is a deprotonated oxygen atom, $\mathrm{Ob}$ is a bridging oxygen atom and $\mathrm{H}$ is a hydrogen atom in a hydroxyl group. Subscripts $\mathrm{N}$ and I will be used to denote whether the atom belongs to a neutral or an anionic fragment, respectively. Using this notation, $\mathrm{Si}_{\mathrm{I}}$ is a silicon atom belonging to an anionic fragment (not to be confused with SI, the ionized monomer) and $\mathrm{Oh}_{\mathrm{N}}$ is a hydroxyl oxygen that belongs to a neutral fragment. Bridging oxygens have two subscripts, since they connect two different fragments, e.g., $\mathrm{Ob}_{\mathrm{II}}$ is a bridging oxygen linked to two anionic fragments.

Let us now begin with the description of the structures of the neutral and anionic monomers. The B3LYP/6-311+G(2d,2p) local geometry of the $\mathrm{Si}(\mathrm{OH})_{4}$ unit, $\mathrm{SN}$, is slightly distorted from a perfect tetrahedral structure, resulting in a $S_{4}$ point group symmetry. In fact, two of the six Oh-Si-Oh angles are $116.1^{\circ}$ while the other four are $106.3^{\circ}$. The rest of the geometric parameters differ negligibly from those reported previously using different exchange-correlation functionals and/or basis sets (Pereira et al., 1999a; Šefč́ík and Goddard III, 2001), but it seems to be clear that the B3LYP Si-Oh distances are smaller than those computed with the BLYP exchangecorrelation functional. Indeed, our geometry is very close to a previous optimization at the MP2/MC6-311G(2d,2p) level (Teppen et al., 1994). The removal of a proton from SN, yielding an SI, results in a species that belongs to the $\mathrm{C}_{3}$ point group symmetry. When compared with the $\mathrm{SN}$ compound, the bond connecting the silicon and the terminal charged oxygen atom in SI is shortened by $\sim 0.08 \AA$ (see the right-hand side of Fig. 1). As a result of this shortening, and in order to prevent the steric influence of the charged Oc atom, the Si-Oh bond lengths are elongated by $\sim 0.05 \AA$. A 
previous DFT optimization of SI at a lower level of theory (Šefćík and Goddard III, 2001) has yielded a structure with no symmetry but which shows the same geometric trends relative to SN.

The optimized structures for the dimers are shown in Fig. 2. The SN2 compound belongs to the $\mathrm{C}_{2}$ point group symmetry and presents two internal $\mathrm{H} \cdots$ Oh bonds with distances equal to 2.467 $\AA$. The Si-Oh bond lengths have values that are close to those computed for SN and the same happens with the Oh-H bond distances. However, in the cases where the hydrogen atoms participate in $\mathrm{H} \cdots \mathrm{O}$ interactions, the $\mathrm{H}-\mathrm{Oh}$ covalent bonds are slightly elongated. The Si-Ob-Si angle is 129.8 . This angle is much smaller than that obtained earlier by Hartree-Fock optimizations of SN2, where it was almost $180^{\circ}$ (Hill and Sauer, 1994; Tossell and Sahai, 2000). However, the present optimized geometry is similar to that computed in the HF study due to Xiao and Lasaga (1996), to that found previously by Pereira et al. (1999a) after DFT calculations, and also to that coming from MP2 calculations as reported by Teppen et al. (1994). Hydrogen bonds between adjacent $\mathrm{SiO}_{4}$ tetrahedra are known to significantly influence the width of the Si-Ob-Si angle (Kubicki and Sykes, 1993), and thus the wider angles observed in previous studies are most likely due to the use of basis sets that do not include enough polarization of the $\mathrm{Si}$ and $\mathrm{O}$ atoms to allow for correct bond hybridization.

The optimized structure for the SNSI compound, which is also shown in Fig. 2, presents a single internal hydrogen bond but it is a very strong one, with an $\mathrm{H} \cdots$ Oc distance of only $1.623 \AA$, and an associated stretched $\mathrm{H}-\mathrm{O}$ bond of $1.018 \AA$. The presence of the strong intramolecular hydrogen bond causes the molecule to bend, relative to SN2, and the Si-Ob-Si angle takes the value of $125.2^{\circ}$. Both the size of the hydrogen bond and local geometry are rather similar to those found in enolic forms of $\beta$-diketones (Gomes and Ribeiro da Silva, 2006). Therefore, one may expect the hydrogen atom in the SNSI species to behave like the hydrogen atom in the simplest $\beta$-diketone (methylacetylacetone), i.e., to be attached alternately to either one of the oxygen atoms that are responsible for the hydrogen bond (Xu et al., 2004). Due to the presence of the negative charge, the 
two Si-Ob bonds differ by $0.45 \AA$, with the longest bond connecting the bridging oxygen atom to the SI unit. The elongation of the Si-Ob bond makes the deprotonated silicate more susceptible to hydrolysis (Kubicki et al, 1996), which can be related to the experimentally observed increase in silica solubility at high $\mathrm{pH}$ (Iler, 1979). Our optimized geometry is qualitatively similar to the one obtained in the HF/6-31G* study of Tossell and Sahai (2000), which shows also a strong H $\cdots$ Oc bond. However, using the same level of theory as Tossell and Sahai (2000), Xiao and Lasaga (1996) have obtained a different geometry, without the $\mathrm{H} \cdots$ Oc bond. We have performed an optimization starting from the structure presented by Xiao and Lasaga (1996), but the end result was less stable by about $19 \mathrm{~kJ} \mathrm{~mol}^{-1}$ than the structure shown in Fig. 2, which we believe to correspond to the global minimum on the PES.

The most stable structure for the SI2 species resembles that described above for the SN2 compound since it presents also two intramolecular hydrogen bonds, but the $\mathrm{H} \cdots \mathrm{O}$ distances are reduced due to the larger charge located at the oxygen atoms. Importantly, this reduction does not lead to the bending of the molecule; the Si-O-Si angle in SI2, $132.2^{\circ}$, is similar to that computed for $\mathrm{SN} 2,129.8^{\circ}$. Furthermore, due to the presence of the charged oxygen atoms attached to each $\mathrm{Si}$, the $\mathrm{Si}-\mathrm{Ob}$ distances are significantly larger than on SN2. It is worth mentioning that we have attempted to optimize a starting geometry where two protons were removed from the same silicon fragment in SN2. However, during the optimization procedure, one of the protons on the neutral fragment migrated to the ionic fragment and the resulting structure was very similar to the minimum portrayed in Fig. 2. The migration of the proton had to be expected since the distances between $\mathrm{H}$ and Oc atoms in the neutral and charged fragments, respectively, are small enough to permit this kind of internal rearrangement, which is aided by the appreciably bent $\mathrm{Si}-\mathrm{Ob}-\mathrm{Si}$ angle. This suggests that molecules where the charges are distributed as evenly as possible among the silicon atoms will be more stable in the gas-phase. Although extrapolations to aqueous solutions are only tentative, it is encouraging that this observation is supported by recent experimental studies (Felmy et al. 2001). 
Several different structures containing three silicon atoms were considered and the most stable geometries are shown in Fig. 3. Due to the increase of the Si-O chain, the most stable structure found for the linear SN3 is folded in such a way that the terminal hydrogen atoms interact with the terminal oxygen atoms on the opposite side of the ${ }^{\cdots}$-Si-O-Si-O- ${ }^{\cdots}$ chain. Further, the structure is highly symmetric possessing a $\mathrm{C}_{2}$ rotation axis. This structure is very similar to that obtained in a previous work where a different exchange-correlation functional was used (Pereira et al., 1999a). The structures optimized for SN2SI, SNSISN and SISNSI are progressively less folded than that of SN3, and present one or more very short Oh- $\mathrm{H}^{\cdots} \mathrm{Oc}$ interactions. The number and relative position of these hydrogen bonds are responsible for the progressive stretching of the chain as the molecule becomes more negatively charged. Ultimately, the ${ }^{\cdots}-\mathrm{Si}$-O-Si-O- $\cdots$ chain in the SI3 compound presents a linear shape, counteracting the folding tendency observed in less charged trimer structures. It should be noted that several starting configurations were folded, but yielded much less stable structures after optimization. Another important aspect that differs from previous anionic trimer structures is that the terminal Oc atoms are not involved in any hydrogen interactions. The linearity of the structure optimized for the SI3 compound stems from the fact that interactions between terminal groups like in SN3 are now very destabilizing due to the presence of Oc atoms. By enforcing such linearity, terminal Oc $\cdots$ Oc unfavorable interactions are eliminated. This phenomenon was already observed in the SI2 structure, where the Oc-Oc, Oc-Ob and Oc-Oh distances are maximized.

The intramolecular condensation of SN3, SNSISN and SI3 leads to the formation of three cyclic structures that are also shown in Fig. 3. In the case of the neutral ring, the internal geometric parameters do not differ significantly from those calculated for SN3 with the exception of the Si-ObSi angles, which are predictably narrower than in the acyclic structure. In an earlier DFT study using the BLYP approach, the most stable structure for the neutral cyclic trimer resembled a chair conformation with three equatorial hydroxyl groups and a system of three hydrogen bonds above the 
ring frame (Pereira et al., 1999a). In that study, this structure (Fig. 6 of Pereira et al., 1999a) was found to be more stable than the structure shown in Fig. 3 for SN3_cyc by $22 \mathrm{~kJ} / \mathrm{mol}$. We have performed several tests at the B3LYP/6-31G(d) level of theory, and could not find any stable structure keeping those three internal hydrogen bonds; in fact, starting from such conformations, the B3LYP/6-31G(d) calculations ended always on the planar and open structure shown in Fig. 3. Visual inspection of the structure of SN3_cyc presented in a later study by the same group (MoraFonz et al., 2005) reveals a planar open geometry, thus supporting the present results.

The most stable geometries for the SN2SI_cyc and SI3_cyc compounds present charged oxygen atoms that are not interacting with hydrogen atoms. In these two compounds the charged oxygen atoms are positioned in such a way that destabilizing $\mathrm{Ob} \cdots \mathrm{Oc}$ interactions are minimized, i.e., they are equatorially positioned with respect to the ${ }^{\cdots}$-Si-Ob-Si- $\cdots$ scaffold. As with terminal Oc atoms in $\mathrm{SI}$, the $\mathrm{Si}-\mathrm{Oc}$ distance is shorter than in cases where the oxygen participates in hydrogen bonds. Importantly, the most stable configuration found for SN2SI_cyc has only one Oh-H ${ }^{\cdots} \mathrm{O}$ short contact while in the SI3_cyc compound, three identical hydrogen bonds are formed. These three bonds afford a high degree of symmetry to the molecular structure of SI3_cyc.

In the case of the silicates presenting four Si atoms, three different types have been studied, i.e., linear, cyclic and branched compounds, with the most stable structures obtained at the B3LYP level of theory shown in Fig. 4. From the analysis of this figure it is understood that the linearly condensed SN4 silicate does not possess a linear structure but it is rather folded, with several short contacts between $\mathrm{O}$ and $\mathrm{H}$ atoms located in non-adjacent groups. The structure obtained in this study is somewhat different from that obtained previously at the BLYP level of theory (Pereira et al., 1999a). In the study by Pereira et al. (1999a), the most stable structure showed a system of four hydrogen bonds between atoms in adjacent groups (similar to those found in the cyclic tetramer, see below). In a test with B3LYP/6-31G(d), we found that this structure is slightly less stable than the one shown in Fig. 4, with H-bonds formed between non-adjacent groups, by $3.4 \mathrm{~kJ} \mathrm{~mol}^{-1}$. 
The SN3SI species presents a very similar structure to that of SN4, but the charged terminal oxygen atom is involved in two very close contacts with two hydrogen atoms from terminal and central silicons, which nevertheless do not appreciably disrupt the molecular shape. Less folded structures were obtained by optimizing the SN2SISN and SI4 compounds, due to the presence of charged oxygen atoms in central positions. The short $\mathrm{Si}-\mathrm{Oc}$ distances prevent the closing of the $\mathrm{Si}-$ $\mathrm{Ob}-\mathrm{Si}$ angles due to destabilizing interactions between bridging and charged oxygen atoms. Furthermore, strong hydrogen bonds are now formed between adjacent groups, thus hindering chain folding. The optimized structure for SI4 appears highly strained, with one outlying deprotonated oxygen pointing outwards on each end of the chain. The effect here is qualitatively similar to that observed for SI3.

As regards the cyclic compounds, the structure optimized for the totally neutral silicate resembles a box with four of the hydroxyl groups interacting with each other in a head-to-tail style, with $\mathrm{H}^{\cdots \cdots} \mathrm{Oh}$ lengths equal to $2.17 \AA$. This structure is identical to that found in a previous DFT study (Pereira et al., 1999a) but different from a recent study that employed a smaller basis set (Monsivais-Gamez et al, 2007). The structure of the SI4_cyc species is much the same as that of SN4_cyc, but the Oh-H groups in equatorial positions are now negatively charged oxygen atoms. As found for the SI3_cyc compound, this configuration is the one that minimizes the destabilizing interaction of the charged atoms with the bridging oxygens while also enabling the preservation of the four stabilizing $\mathrm{Oh}-\mathrm{H}^{\cdots} \mathrm{O}$ Ch contacts. As a result of ionization, these hydrogen bonds become shorter than in SN4_cyc, but the ring scaffold does not become more strained.

Six different types of branched silicate tetramers were fully optimized at the B3LYP level of theory and are also depicted in Fig. 4. The first four of these were obtained by condensation of three terminal hydrogens, in either the neutral or the charged monomer, with SN or SI units. In all four cases considered, it is quite clear that the final structures maintain a trigonal aspect around the central Si-Oh or Si-Oc axis. In the cases where the central group is neutral, the structure is stabilized 
by hydrogen bonds between atoms in the three terminal branches. When the central group is anionic, on the other hand, the stabilizing bonds are formed between terminal hydrogens and the central negative oxygen. As a consequence, the Si-Ob-Si angles of (SI)-3SN and (SI)-3SI are significantly smaller than those of (SN)-3SN and (SN)-2SN,SI. The structure of (SN)-3SN may be compared to that presented in the earlier DFT study of Pereira et al. (1999b). The latter is much more open than our structure, and from re-calculations at the B3LYP/6-31G(d) level of theory it was found to be less stable by $20.2 \mathrm{~kJ} \mathrm{~mol}^{-1}$.

The other two branched tetramers were obtained by condensing an SN3_cyc scaffold onto either a neutral or an ionized monomer. In these cases, the structure of the SN3_cyc moiety is only slightly changed when compared with the SN3_cyc trimer, but in the case of the branched tetramers some atoms of the cyclic unit are involved in hydrogen bonds with terminal atoms. These bonds have much the same configuration in both neutral and single-charged forms, giving the same overall shape to the two molecules but with a higher degree of Si-Ob-Si bending in the latter. Our structure for (SN)-SN3_cyc is very different from the less stable geometry presented by Pereira et al. (1999b), which shows a system of three hydrogen bonds between adjacent hydroxyl groups in the trimer ring with the branched monomer positioned equatorially.

The optimized structures for some selected silicate pentamers are shown in Fig. 5. With the exception of the SI5 species, the other linear compounds studied, namely, SN5, SN4SI, SN3SISN and SN2SISN2, do not present a linear conformation after geometry optimization and are folded by hydrogen bonds so as to form cages. As in the case of the linear tetramer, ionization of a terminal oxygen does not cause major disruption to the molecular structure. However, this disruption increases as we move the negatively charged oxygen to the center of the chain, favoring less folded structures. As already found for the SI3 and SI4 compounds, the SI5 compound is stretched, with the terminal charged oxygen atoms once more pointing away from the silicate chain.

Three branched pentamers were considered, obtained by condensing four neutral or anionic 
monomers onto a central neutral monomer. All cases studied present structures with four silicon atoms almost positioned in the same plane, one of these silicons surrounded by the other three, and a fifth one located directly above the central silicon atom. These pyramidal configurations permit interactions between the $\mathrm{Oh}-\mathrm{H}$ groups in the three external silicon atoms and those from the out-ofplane silicon. The (SN)-4SI structure is peculiar, in the sense that none of its charged oxygens participates in hydrogen bonds - instead, three of them are located in an equatorial position relative to the pyramid "base" and pointing outwards, while the fourth Oc is pointing upwards. This behavior is analogous to that found previously for the highly charged linear tetramer and pentamer.

In Tables 1 and 2, we show the average and standard deviation, calculated over all molecules studied, for each bond length and angle, respectively. From Table 1, one can see that the Si-Oh bonds tend to be longer in anionic fragments than in neutral ones, showing also more variability in the former. This bond elongation results from the influence of the negatively charged oxygen attached to the same silicon, as observed, for instance, in the case of the SI monomer. This effect is very strong in the highly deprotonated molecules, but weaker in less ionized molecules, which leads to the high variability. The same trend can be observed for the Si-Ob bonds, with longer bonds involving anionic fragments. Interestingly, Si-O bond lengths in general depend only on the nature of the fragment (anionic vs neutral) and are statistically independent of the nature of the oxygen (hydroxyl vs bridging). Predictably, Si-Oc bonds are significantly shorter, due to the absence of a charge-compensating atom attached to the oxygen. Thus, one can speak of three generic $\mathrm{Si}-\mathrm{O}$ bonds: $\mathrm{Si}_{\mathrm{N}}-\mathrm{O}$ (average of $1.64 \AA$ ), $\mathrm{Si}_{\mathrm{I}}-\mathrm{O}$ (average of $1.68 \AA$ ) and $\mathrm{Si}_{\mathrm{I}}-\mathrm{Oc}$ (average of $1.58 \AA$ ). As for Oh-H bonds, their length is statistically independent of the nature of the fragment, but is affected by the participation of the group in hydrogen bonds. Indeed, the Oh-H covalent bond length (average of $0.959 \AA$ in non-donor groups) increases when the hydroxyl group acts as a proton donor to the oxygen atom of another hydroxyl group (average of $0.971 \AA$ ) or, even more significantly, to a negatively charged oxygen atom (average of $0.996 \AA$ ). These observations suggest 
that the latter hydrogen bonds are quite strong, and significantly influence the geometries of charged species, as discussed above.

From Table 2, one can see that the Si-Oh-H angle is smaller for anionic fragments. Once more, this is due to the influence of the deprotonated oxygen atom, as manifested in the SI structure. In tune with the above analysis of the bond lengths, the O-Si-O angles depend only on the nature of the fragment and on the charge of the oxygen. Therefore, all angles with $\mathrm{Si}_{\mathrm{N}}$ atoms at the center are statistically indistinguishable, with a global average of $109.6^{\circ}$, while angles between two neutral oxygens with an $\mathrm{Si}_{\mathrm{I}}$ atom at the center show a global average value of $104.9^{\circ}$. Finally, $\mathrm{O}-\mathrm{Si}_{\mathrm{I}}-\mathrm{Oc}$ angles are significantly wider, with a global average of $114.2^{\circ}$. Indeed, the structure of the anionic monomer illustrates nicely the global trend, with deprotonation inducing narrower Oh-Si-Oh angles and wider Oh-Si-Oc angles. A final aspect worth noticing is the high standard deviation of the SiOb-Si angle, in agreement with previous experimental (Durig et al., 1977) and theoretical (Hill and Sauer, 1994; Teppen et al., 1994; Pereira et al., 1999a, 1999b; Murashov, 2003) results that have demonstrated the high flexibility of this angle. This flexibility is the main reason for the large variability of silicate species observed in nature, and for the ability of silica to form highly stable crystalline porous solids - zeolites.

Calculated ${ }^{29} \mathrm{Si},{ }^{17} \mathrm{O}$ and ${ }^{1} \mathrm{H}$ NMR chemical shifts for all silicates studied are given in the Electronic Annex EA-2, while Electronic Annex EA-3 contains average values of the ${ }^{29}$ Si chemical shifts according to the degree of substitution (DOSub), i.e., the number of bridging oxygens connected to a silicon atom. The calculated ${ }^{29} \mathrm{Si}$ shift for the $\mathrm{SN}$ species is $-73.1 \mathrm{ppm}$, which is in excellent agreement with the experimentally derived value in organic solution, -72.0 ppm (Unger et al., 1984). The ${ }^{29} \mathrm{Si}$ shifts for the dimer, linear trimer and cyclic trimer are similar to those calculated previously by Moravetski et al. (1996) using coupled-perturbed Hartree-Fock and polarized basis sets, also with the GIAO method. Our values for the cyclic tetramer are significantly different from those of Moravetski et al. (1996) probably because these authors considered a planar geometry for 
the SN4_cyc compound which is not the most stable. Since the ${ }^{29}$ Si chemical shifts seem not to be very sensitive to both the computational method and size of basis set, we believe that the results reported in the Electronic Annex EA-2 may be used as reference for comparison with experimental NMR data. Indeed, the averages according to DOSub (see EA-3) are within the range of corresponding values reported experimentally (e.g., Haouas and Taulelle, 2006).

\subsection{Atomic charges of neutral and anionic silicates}

Partial atomic charges on the monomers, shown in Table 3, were calculated using three different standard methods: Mulliken, CHelpG and NPA. For the neutral monomer, all methods give qualitatively similar charge distributions - high positive charge on the silicon, negative charge on the oxygens and small positive charge on the hydrogens. However, the methods differ quantitatively. The Mulliken charges on each atom are lower in magnitude than the NPA charges by an approximately constant amount (about 0.3 a.u.), being the NPA charges much more chemically reasonable. This has to be expected since in the Mulliken analysis the overlap population is evenly divided between the two neighboring atoms without consideration of their nature and electronegativity. The NPA method, however, is significantly more accurate and it is also almost basis set independent when compared with the Mulliken method, but the latter charges are still used since they are calculated easily. CHelpG charges are also lower in magnitude than NPA charges, but the variation is not constant: silicon atoms are much less positive, while charges on hydrogen atoms are almost the same. The different variations found for NPA and CHelpG charges are due to the different computational strategies used to derive their values. The former is a molecular orbitalbased method while the latter fits the charges to the electrostatic potential calculated in a regularly spaced grid of points around the molecule under the constraint that the dipole moment is preserved. 
When we remove one proton from the neutral monomer, yielding an SI, the excess negative charge is distributed throughout the molecule. This partition differs substantially according to the method used. With NPA, the silicon and hydrogen atoms become less positive and the oxygens more negative. As expected, the deprotonated oxygen has a significantly more negative charge than the other oxygens. Thus, the excess negative charge is distributed gradually along the SI molecule, first to the deprotonated oxygen (a change of -0.262 a.u. relative to the hydroxyl oxygen in SN), then to the silicon (-0.088 a.u. change) and finally to the hydroxyl groups (-0.050 a.u. change for each O-H group). With $\mathrm{CHelpG}$, the change of charge in the Oc atom (-0.266 a.u.) is practically the same as with NPA. However, the decrease of the $\mathrm{H}$ charge is comparatively much larger $(-0.138$ a.u.) with CHelpG. More importantly, the silicon atom and the hydroxyl oxygens become more positive in the anionic monomer than in the neutral monomer when CHelpG is used, which is counterintuitive.

The trends with CHelpG are even more unexpected when one considers deprotonation in the dimer (see Table 4). In this case, a first deprotonation causes both silicon atoms to become less positive, as should be expected. However, the Si atom belonging to the anionic fragment of SNSI is more positive than that of the neutral fragment. Moreover, both types of Oh atoms become less negative in the ionized molecule, which once again is counterintuitive. A second deprotonation leads to a strong increase in the Si charge, and these atoms become even more positively charged in SI2 than in SN2. NPA charges, on the contrary, show the expected trends on progressive deprotonations. Tossell and Sahai (2000) compared charges obtained using a natural bond orbital analysis with potential derived charges (PDC), which are calculated using a procedure similar to CHelpG, for a few neutral silicates. Interestingly, they concluded that the PDC charges changed rather erratically on successive polymerizations (Tossell and Sahai, 2000). Similarly erratic behavior was found by Murashov (2003), who compared NPA and CHelpG charges for the neutral and anionic forms of the monomer, dimer, linear trimer, branched tetramer and branched pentamer. 
A further analysis of our CHelpG charges for larger silicates reveals equally inconsistent results, which suggests that this method is not adequate for explaining general trends in charge distribution on deprotonation and condensation of silicates, at least for isolated molecules in the gas phase. Thus, except where explicitly noted, all further analysis in this section is based solely on NPA charges. It should be mentioned, however, that the inadequacy of CHelpG for describing charge distribution trends on deprotonation of the silicates considered in this work does not detract from other merits of this methodology. In fact, when one compares the results for the multipole moments and the electrostatic potential calculated from the wave function and from the CHelpG or NPA charges, the quality of the CHelpG charges is found to be superior to that of the molecularorbital based methods (Sigfridsson and Ryde, 1998). In fact, NPA charges are unsuited for use when electrostatic properties are of interest (Sigfridsson and Ryde, 1998) while CHelpG charges are usually preferred for incorporation in molecular mechanics force fields for modeling in an aqueous environment (Carlson et al., 1993). Extensive tables with NPA partial charges for all silicates studied are provided in the Electronic Annex EA-2. In the remainder of this section, we will discuss the effects of deprotonation, chain length and molecular shape (linear, cyclic or branched) on the charge distribution in the molecule, and present only the results necessary to illustrate particular trends.

Returning to the deprotonation of the dimer, as we go from SN2 to SNSI to SI2 the net charge on the molecule increases from 0 to -1 and then to -2 . One can imagine two limiting cases to describe the distribution of this excess charge, i.e., (i) the charge is distributed uniformly throughout the molecule, or (ii) the charge is concentrated only on the deprotonated oxygen. As is usually the case, reality lies somewhere between these two extremes - some of the excess charge remains at the deprotonated oxygen and the remainder is spread along the other atoms. To better illustrate the distribution of charge in larger silicates, we adopt the following strategy: each molecule is divided into fragments that contain one Si atom, together with every connected oxygen and/or hydroxyl 
group; the net charge on each fragment is computed by adding the point charge of every atom in the fragment; in case of a bridging oxygen, its charge is split equally between the two adjacent fragments. Thus, the neutral dimer is composed of two SN fragments, the single-charged dimer consists of one $\mathrm{SN}$ and one SI, and so on.

In a neutral silicate, by definition, the sum of charges of all fragments must be zero. However, this does not impose that the charge on each fragment be zero - factors such as molecular structure and hydrogen bonding may induce local charge fluctuations. For the symmetric neutral dimer, these fluctuations are negligible, and the net charge on each SN fragment is indeed zero. Other molecules, such as the folded SN4, show some fluctuations (net charges around \pm 0.006 a.u. on each fragment). A similar analysis for all neutral silicates reveals that the fluctuations are larger in asymmetric structures that possess many hydrogen bonds (such as SN4 and SN5, for example), but are generally below 0.01 a.u.. By analogy, it may be expected that the net charge on each SI fragment belonging to a molecule with one charge per silicon (i.e., composed of only SI fragments) be very close to -1 . This is indeed the case, but fluctuations in asymmetric molecules with hydrogen bonds (e.g., SI5) are comparatively larger than in neutral molecules, reaching up to 0.05 a.u..

In molecules with intermediate degrees of deprotonation, net charges of neutral fragments tend to be more negative than in fully neutral molecules, while those of anionic fragments are less negative than in fully anionic molecules, i.e. with one negative charge per Si. For example, SNSI shows net charges of -0.116 a.u. on the SN fragment and -0.894 a.u. on the SI. Both single-charged linear trimers (SN2SI and SNSISN) have net charges between -0.070 and -0.077 a.u. on the SN fragments and between -0.854 and -0.858 a.u. on SI, while SISNSI has values of -0.130 a.u. on SN and -0.935 a.u. on each SI. The trend observed in these molecules suggests that it is the charge per silicon (CPS) on each molecule that controls the charge distribution along the fragments. To verify this, we have plotted in Fig. 6 the net charge on neutral (closed symbols) and ionic (open symbols) fragments as a function of CPS for all silicates studied. It is clear that there is a decreasing trend in 
the fragment net charge as the molecule becomes more negatively charged. The limiting cases, as discussed above, are zero for SN fragments in a neutral silicate and -1 for SI fragments in a fully ionized silicate. The data are very well described by the following linear expressions, which respect the limiting values:

$$
\begin{aligned}
& q_{\mathrm{SN}}=0.2 C P S \\
& q_{\mathrm{SI}}=-0.8+0.2 C P S
\end{aligned}
$$

Here, $q_{\mathrm{SN}}$ and $q_{\mathrm{SI}}$ denote the net charge on neutral and anionic fragments, respectively. It should be noted that similar plots of the fragment charge as a function of different variables (total molecular charge, degree of substitution, etc.) yielded no clear trend. An interesting corollary of the linear fits to the fragment charge is that the limiting value for the net charge on an SI fragment as the CPS tends to zero is -0.8 a.u.. In other words, if we remove a proton from a very large neutral silicate, the charge on the ionized fragment will be close to -0.8 a.u.. This may be important, for example, in the study of ionic sites on the surface of colloidal silica particles.

If the CPS on the molecule controls the distribution of net charge in different fragments, it is reasonable to expect that it has an effect on the point charge of individual atoms. These charges, however, are much more sensitive to local effects, such as molecular structure and hydrogen bonding. An interesting example, though, is the influence of CPS on the total charge of hydroxyl groups, which is plotted in Fig. 7. By considering the hydroxyl group as a whole, we compensate for local effects due to hydrogen bonds - if an $\mathrm{OH}$ group participates in a bond, the charge on the hydrogen becomes more positive and the oxygen charge more negative, but the total charge on the group is almost the same (see, e.g., the SI2 molecule). The scatter is larger than in Fig. 6, but one can still distinguish a linear increase in hydroxyl charge with CPS. Moreover, the net charge on hydroxyl groups belonging to both neutral and anionic fragments statistically lie on the same straight line, given by:

$$
q_{\mathrm{OH}}=-0.59+0.077 C P S
$$


where $q_{\mathrm{OH}}$ denotes the total charge on the hydroxyl group (Oh charge plus $\mathrm{H}$ charge). Plots of point charges on individual atoms as a function of CPS are even more scattered, and are not shown here. Nevertheless, the trends suggest that an increase in the magnitude of the charge per silicon (from 0 to -1$)$ causes all oxygen atoms $(\mathrm{Oh}, \mathrm{Oc}$ and $\mathrm{Ob})$ to become more negative and, to a lesser extent, $\mathrm{Si}$ and $\mathrm{H}$ atoms to become less positive.

Apart from the strong effect of the CPS on the charge distribution in the molecule, other more subtle effects can be distinguished by analyzing our data. In particular, it becomes clear that the charge on the silicon atom depends on the degree of substitution (DOSub) of that atom. The degree of substitution of an Si can be defined as the number of bridging oxygens connected to that Si. Thus, the DOSub of a monomer is zero, that of the central Si in the linear trimer is 2 and that of the central $\mathrm{Si}$ in the branched pentamer is 4 (the maximum degree for a tetra-coordinated silicon). In Fig. 8, we plot the point charge on Si atoms belonging to neutral and anionic fragments as a function of the DOSub of the silicon. Even disregarding the effect of the charge per silicon (the main responsible for the scatter in the data), it is clear that the charge on both $\mathrm{Si}_{\mathrm{N}}$ and $\mathrm{Si}_{\mathrm{I}}$ atoms increases with the DOSub. This is due to the higher electron-withdrawing effect of the $\mathrm{Ob}-\mathrm{Si}$ group relative to the Oh-H group (Iler, 1979), and agrees with previous theoretical studies (Pereira et al., 1999b; Tossell and Sahai, 2000; Murashov, 2003), as well as with experimental evidence from NMR (Lippmaa et al., 1980). Moreover, the charge on $\mathrm{Si}_{\mathrm{N}}$ tends to be higher than that on $\mathrm{Si}_{\mathrm{I}}$, but the effect of DOSub is the same in both cases. In fact, the data are well described by linear fits with the same slope:

$$
\begin{aligned}
& q_{\mathrm{Si}_{\mathrm{N}}}=2.39+0.031 \text { DOSub } \\
& q_{\mathrm{Si}_{\mathrm{I}}}=2.32+0.031 \text { DOSub }
\end{aligned}
$$

The fact that the slope is precisely the same is probably fortuitous, but it is reasonable to expect a similar effect of DOSub on both neutral and anionic fragments. We have also plotted the point charges on other atoms as a function of the DOSub of the silicon to which they are attached. In all 
cases, the scatter was large and no clear trends were distinguished.

Beside these two major effects - charge per silicon and degree of substitution - it is possible that other variables also affect the charge distribution. For example, the charge on a silicon atom may depend on the charge around its immediate neighbors. Indeed, some of our results suggest that $\mathrm{Si}_{\mathrm{N}}$ atoms that are directly connected to an SI fragment may be slightly less positive than when they are connected to other SN fragments (e.g., in SN3SISN, the terminal silicon connected to the ionic fragment, point charge of 2.409 a.u., is less positive than the other terminal silicon, 2.417 a.u., while the inner silicon connected to the ionic fragment, point charge of 2.449 a.u., is also less positive than the other inner silicon, 2.463 a.u.). However, these very small differences cannot be clearly distinguished from statistical fluctuations, and therefore the charge is not strongly influenced by the chemical neighborhood of the fragment. Similarly, our data suggest that Si atoms in cyclic silicates may be less positive than in the corresponding linear silicates (e.g., charges on Si atoms of SN3_cyc are all between 2.439 and 2.446 a.u., while the charge of the inner silicon atom in SN3 is 2.460 a.u.), but once again these differences cannot be discerned statistically. Therefore, it may be concluded that the charge distribution on the atoms of a silicate depends mostly on the charge per silicon in the molecule - the higher the CPS, the more negative the atomic charge - and, for Si atoms, on the degree of substitution - the more condensed the silicon atom, the more positive its

charge. Effects of other variables are likely to be of minor importance. These observations are of significant importance for the future development of a force field that is able to cope with both neutral and anionic silicates.

\subsection{Energetics of deprotonation and of condensation}

The absolute enthalpies and Gibbs free energies, at $T=298.15 \mathrm{~K}$, for all the studied silicates 
are given in the Electronic Annex EA-2. Using these values, the enthalpies of deprotonation of the silicate compounds in the gas-phase, $\Delta H_{\text {dep }}$, were calculated from the following generic reaction at $T=298.15 \mathrm{~K}:$

$$
\mathrm{SN}_{x} \mathrm{SI}_{y} \leftarrow \mathrm{SN}_{x-n} \mathrm{SI}_{\mathrm{y}+\mathrm{n}}+n \mathrm{H}^{+} \quad n \leq x ; x+y \leq 5
$$

where SN and SI labels are used for neutral or ionic fragments, respectively, in linear, branched or cyclic polymers, as described in the previous sections. For example, in the case of a neutral monomer, i.e., SN species, the subscript $x$ is 1 and the subscript $y$ is 0 and, therefore, the deprotonation of $\mathrm{SN}$ will produce $\mathrm{SI}$ and $\mathrm{H}^{+}$. We have also calculated deprotonation enthalpies accounting for solvation of the intervening species by a continuum model solvent (see section 2). These were calculated according to the following reaction:

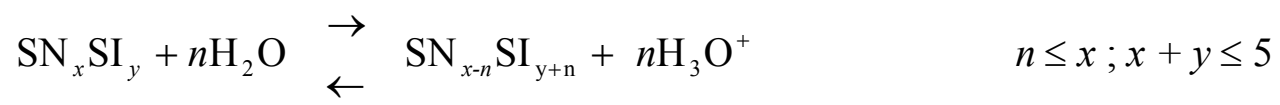

The B3LYP/6-311+G(2d,2p) computed deprotonation enthalpies for the compounds studied are reported in Table 5 as total values obtained directly from the computation of the enthalpy of the reaction shown by eq. (4) or as total values divided by the number of protons, $n$, removed from the parent neutral compound. The enthalpies calculated within the SCRF approach, via eq. (5), are shown in parenthesis. It should be emphasized that the SCRF enthalpies were obtained from singlepoint calculations, without further geometry optimization, and as such should only be taken as indicative values. Direct comparison between different species must be interpreted with care, since 
the solvent is expected to have a significant effect on the optimal geometry of the intervening species, the study of which requires the use of several explicit solvent molecules. Such a study is already quite demanding for simple silicates (Tossell and Sahai, 2000; Kubicki, 2001) and a detailed inspection of the potential energy surface, like the one performed in this work for the gas-phase silicates, would require prohibitive computational resources.

The calculated gas-phase enthalpy for the first deprotonation of the SN compound, yielding the SI anion, is $1473.7 \mathrm{~kJ} / \mathrm{mol}$ at $T=298.15 \mathrm{~K}$ and is $1467.7 \mathrm{~kJ} / \mathrm{mol}$ at $T=0 \mathrm{~K}$. These values are compared in Table 6 with those computed previously by Murashov (2003) at the B3LYP/6$31+\mathrm{G}(\mathrm{d}, \mathrm{p})$ level of theory, by Kubicki et al. (1995) using G2 theory, by Rustad et al. (2000) with the B3LYP/6-311++G(d,p) approach, and by Šefčík and Goddard III (2001) with the B3LYP/6$31+\mathrm{G}(\mathrm{d}, \mathrm{p}) / / \mathrm{B} 3 \mathrm{LYP} / 6-31 \mathrm{G}(\mathrm{d}, \mathrm{p})$ approach. All of these results are in close agreement with each other and with our own calculations (the small but noticeable differences are mainly due to the consideration of different basis sets). Furthermore, Šefč́ik and Goddard III (2001) have concluded that $\mathrm{B} 3 \mathrm{LYP} / 6-31+\mathrm{G}(\mathrm{d}, \mathrm{p}) / / \mathrm{B} 3 \mathrm{LYP} / 6-31 \mathrm{G}(\mathrm{d}, \mathrm{p})$ calculations give results for the deprotonation energy that are similar to MP2//6-31++G(d,p) values (difference smaller than $4 \mathrm{~kJ} / \mathrm{mol}$ ). Our results are also in remarkably good agreement with the G2 calculations of Kubicki et al. (1995).

Mora-Fonz et al. (2005) used a different reaction to calculate the energies of deprotonation, where a proton from the $\mathrm{SN}$ species reacts with $\mathrm{HO}^{-}$producing $\mathrm{H}_{2} \mathrm{O}$ as shown in eq. 6 .

$\mathrm{SN}+\mathrm{HO}^{-} \underset{\mathrm{NI}}{\leftarrow}+\mathrm{H}_{2} \mathrm{O}$

Our B3LYP/6-311+G(2d,2p) result for the standard enthalpy of the reaction of deprotonation described by eq. 6 is $-158.8 \mathrm{~kJ} / \mathrm{mol}$. At the same level of theory, the Gibbs free energy calculated for 
the same reaction is $-165.0 \mathrm{~kJ} / \mathrm{mol}$. This value compares well with the result of Šefćík and Goddard III (2001), -161.8 kJ/mol, but differs by more than $60 \mathrm{~kJ} / \mathrm{mol}$ from that calculated by Mora-Fonz et al. (2005), $-229 \mathrm{~kJ} / \mathrm{mol}$. It is unlikely that this difference is due to the different temperatures at which the Gibbs free energies were computed. Nevertheless, to test this hypothesis, we have calculated the thermal corrections corresponding to a temperature of $T=450 \mathrm{~K}$ (the value used by Mora-Fonz et al. (2005)). The result thus obtained, $-168.0 \mathrm{~kJ} / \mathrm{mol}$, is very close to the value at $T=298.15 \mathrm{~K}$, and still very different from the result of Mora-Fonz et al. (2005).

Another possible source for the discrepancy is due to the different basis sets employed. Our work uses a larger basis set than the DNP basis set (equivalent to the $6-31 G(d, p)$ basis) used by Mora-Fonz et al. (2005), augmented by the incorporation of diffuse functions. Šefč́ík and Goddard III (2001) calculated the enthalpy of deprotonation for $\mathrm{SN}$ yielding $\mathrm{SI}$ and $\mathrm{H}^{+}$species at the B3LYP/6-31G(d,p) and B3LYP/6-31++G(d,p) levels of theory and found that the values computed with each of these basis sets differed by $56.5 \mathrm{~kJ} / \mathrm{mol}$. Furthermore, these authors emphasized the importance of incorporating diffuse functions in the calculations in order to obtain accurate energy values. The enthalpy of the reaction shown in eq. 6 was re-calculated after re-optimization of the structures presented in section 3.1 with the $6-31 \mathrm{G}(\mathrm{d}, \mathrm{p})$ basis set and the B3LYP functional. The value obtained is much more negative, i.e., $-267.6 \mathrm{~kJ} / \mathrm{mol}$, showing the dramatic effect of the absence of diffuse functions on the computed enthalpy. Furthermore, a single-point B3LYP/6$31+G(d, p)$ energy calculation on the B3LYP/6-31G(d,p) optimized structures yields an enthalpy at $T=298.15 \mathrm{~K}$ (thermal corrections determined with the basis set without diffuse functions) for the same deprotonation reaction of $-154.4 \mathrm{~kJ} / \mathrm{mol}$, which is now very close to the values computed using the larger basis set. It is worth noticing that this value is similar but not identical to that computed by Šefčík and Goddard III (2001), -158.4 kJ/mol. The latter value was obtained with a different computational code, where the LYP functional includes the VWN-5 local density correlation functional due to Vosko et al. (1980) while the Gaussian code used in our work adopts the VWN-3 
functional. The small difference found between the deprotonation enthalpies calculated with the B3LYP/6-311+G(2d,2p) approach (i.e., both optimization and vibrational frequencies calculated with this large basis set), and with the B3LYP/6-31+G(d,p)//B3LYP/6-31G(d,p) approach (i.e., combining a smaller basis set to compute the vibrational frequencies with a larger one for the computation of the energy of the system) is not new in the literature (Gomes and Ribeiro da Silva, 2004, 2005)

Finally, in order to check if the BLYP approach could be associated with the discrepancy mentioned above, the BLYP functional was also combined with the $6-31 \mathrm{G}(\mathrm{d}, \mathrm{p})$ basis set in the computation of the enthalpy of deprotonation of SN by hydroxyl. At the reference temperature, $T=298.15 \mathrm{~K}$, the calculated enthalpy of deprotonation is $-281.9 \mathrm{~kJ} / \mathrm{mol}$ and the corresponding Gibbs free energy is $-288.0 \mathrm{~kJ} / \mathrm{mol}$. At $T=450 \mathrm{~K}$ this value is slightly changed to $-291.0 \mathrm{~kJ} / \mathrm{mol}$, which still differs largely from that reported by Mora-Fonz et al. (2005). Therefore, the source for such a discrepancy seems to come from the consideration by those authors of different geometries for at least one of the species included in the deprotonation reaction described by eq. 6 . This example demonstrates that one must exercise care in the choice of basis set and in the geometry optimizations in order to obtain correct energies for reactions involving silicate species.

In the case of the SN2 species, the removal of a single proton to produce a gaseous proton and an SNSI molecule costs $1402.1 \mathrm{~kJ} / \mathrm{mol}$; when compared with the deprotonation enthalpy calculated for $\mathrm{SN}$, this value is $\sim 70 \mathrm{~kJ} / \mathrm{mol}$ lower (when solvation effects are taken into account, this difference is reduced to $32 \mathrm{~kJ} / \mathrm{mol}$ ). This observation can be related to the calculated NPA charges described in section 3.2, since the negative charge is spread over a larger number of atoms in the case of SNSI than on SI. In the case of SI2, the energy required for removal of the second proton is $1810.4 \mathrm{~kJ} / \mathrm{mol}$, which, as expected, is significantly higher than the energy of the first deprotonation. The average deprotonation enthalpy, calculated as the total enthalpy divided by the number of 
protons removed, is $1606.3 \mathrm{~kJ} / \mathrm{mol}$ for SI2. $\Delta H_{\text {dep }} / n$ increases with the size of the silicate - it is $1710.5 \mathrm{~kJ} / \mathrm{mol}$ in the case of SI3, $1800.8 \mathrm{~kJ} / \mathrm{mol}$ in the case of SI 4 and $1877.8 \mathrm{~kJ} / \mathrm{mol}$ in the case of SI5 - which suggests that the presence of highly deprotonated large silicates may not be favorable. However, a close analysis of these values, more precisely, of the differences between $\mathrm{SI}_{y+1}-\mathrm{SI}_{y}$ where $y$ is an integer between 1 and 4, reveals that the difference is reduced with the increase of the number of silicon atoms. This trend can be observed as a slight curvature in Fig. 9a, where $\Delta H_{\text {dep }} / n$ of increasingly large $\mathrm{SI}_{\mathrm{y}}$ compounds is plotted. Moreover, the inclusion of solvent effects (albeit at a very simplified level) practically eliminates these differences; the value of $\Delta H_{\text {dep }} / n$ computed with solvation effects is almost constant for fully charged silicates.

The analysis of the larger "linear" silicates suffering single deprotonations, i.e., SN2SI, SNSISN, SN3SI, SN2SISN, SN4SI, SN3SISN and SN2SISN2, permits to conclude that the enthalpy of the first deprotonation tends to stabilize with an increase in the number of silicon atoms, in agreement with a previous study (Kubicki et al., 1996). The variation of $\Delta H_{\text {dep }}$ with the number of silicon atoms is depicted in Fig. 9b for the most energetically favorable situation, i.e., when the proton is removed from an $\mathrm{OH}$ group attached to a silicon atom at the end of the polymeric chain. The enthalpic variation with the size of the silicate presents a clear curvature suggesting a rapid stabilization of the acidity of linear silicates. It is encouraging to see that this trend is analogous to the experimentally observed increase in silicate acidity with degree of condensation (Iler, 1979; Šefč́́k and McCormick, 1997).

The enthalpy required to deprotonate a central hydroxyl group in a linear silicate is larger than that required to deprotonate a terminal one; for example, $\Delta H_{\text {dep }}$ computed for SN4SI is $5 \mathrm{~kJ} / \mathrm{mol}$ lower than that computed for SN3SISN and $21 \mathrm{~kJ} / \mathrm{mol}$ than that calculated for SN2SISN2 (the trend is similar when solvation effects are included). This finding seems to be due to the much more compact structure optimized for SN4SI than for the other two single-charged pentamers. A similar 
conclusion may be retrieved for SN3SI and SN2SISN species where the former is much more compact than the latter. Also important, the geometry optimized for the former compound resembles more closely the structure of the SN4 species, suggesting that the negative charge at the end of the chain induces a small perturbation in the geometry and, hence, the global stability is almost unaffected.

Regarding cyclic silicates, the analysis of the data reported in Table 5 shows that the enthalpies required to deprotonate a hydroxyl group from cyclic silicates are larger by $30-60 \mathrm{~kJ} / \mathrm{mol}$ than those calculated for acyclic structures. This is possibly due to the rigid geometry of the cyclic species, which prevents the formation of crucial internal hydrogen bonds that aid the redistribution of the negative charge throughout the molecule. However, the comparison above must be taken with some caution since the number of hydroxyl groups per silicon atom is smaller in the cases of the cyclic structures than in the acyclic ones. Once again, when solvation effects are considered, the differences between cyclic and linear deprotonation enthalpies are significantly reduced, which suggests that cyclic anionic silicates should be relatively more stable in aqueous solutions.

Despite the consideration of only a few branched charged silicates, the degree of branching seems to have a small effect on the calculated deprotonation enthalpies (with or without consideration of solvation effects). In fact, the calculated $\Delta H_{\text {dep }}$ for (SN)-2SN,SI and (SI)-3SN are included in the interval defined by the enthalpies of the corresponding single-charged linear isomers (SN3SI and SN2SISN). Similarly, the deprotonation enthalpy of (SN)-3SN,SI is close to those of SN4SI, SN3SISN and SN2SISN2. The similar calculated deprotonation enthalpies for branched and linear silicates suggest that, thermodynamically speaking, the formation of branched species is not due to a better stabilization of the negative charge in these compounds. As we will see below, this is not the case in the formation of rings.

Apart from deprotonation equilibria, silicate speciation is also controlled by 
hydrolysis/condensation equilibria. These can be represented, using our notation, by the following generic reactions, where $x+y \leq 5$ :

$$
\begin{array}{rll}
x \mathrm{SN}+y \mathrm{SI} & \longrightarrow \mathrm{SN}_{x} \mathrm{SI}_{y}+(x+y-1) \mathrm{H}_{2} \mathrm{O} & \text { linear; branched } \\
x \mathrm{SN}+y \mathrm{SI} & \longrightarrow \mathrm{SN}_{x} \mathrm{SI}_{y}+(x+y) \mathrm{H}_{2} \mathrm{O} & \text { cyclic }
\end{array}
$$

The computed enthalpies of condensation ( $\left.\Delta H_{\text {cond }}\right)$ at $T=298.15 \mathrm{~K}$ according to these reactions are also reported in Table 5 (with and without consideration of solvation effects). The value reported in the third column is the total enthalpy of formation of an oligomer from the individual monomeric building blocks (e.g., condensation of 3 neutral monomers and one anionic monomer to yield an SN3SI oligomer). In the fourth column, we report the total value divided by the number of water molecules produced during the reaction (e.g., for SN3SI three water molecules are produced, while for SN4_cyc four water molecules are produced). At this point, it is worth emphasizing that we are concerned only with studying thermodynamic trends in reactions involving silicates, and we make no considerations about reaction kinetics. The mechanisms of some condensation reactions involving neutral and anionic silicates have been the subject of a recent computational study (Trinh et al., 2006).

Examining the results for the dimerization reactions, we can see that the formation of a neutral dimer from two neutral monomers is thermodynamically favorable $(-15.1 \mathrm{~kJ} / \mathrm{mol})$. When the reaction occurs between one neutral and one charged monomer, to yield an SNSI, it is even more favorable. Our result for $\Delta H_{\text {cond, }}-86.7 \mathrm{~kJ} / \mathrm{mol}$, compares well with the gas-phase value for the same reaction calculated recently by Trinh et al. (2006), $-92 \mathrm{~kJ} / \mathrm{mol}$. The large decrease of $\Delta H_{\text {cond }}$ relative 
to the neutral dimerization results from the fact that in SNSI the negative charge is distributed over more atoms than in SI. This effect is also responsible for the higher deprotonation enthalpy of SN2 relative to SN, as reported above. A similar reasoning can explain why the formation of a doublecharged dimer from two SI units is thermodynamically very unfavorable $(+250.0 \mathrm{~kJ} / \mathrm{mol})$. In this case, the negative charge density in the SI2 molecule is much higher than in the two isolated SI units. An analogous trend can be observed in the enthalpies of formation of linear trimers - they go through a minimum as we increase the number of charges on the product (compare $\Delta H_{\text {cond }}$ for SN3, SN2SI, SNSISN, SISNSI and SI3). The picture is somewhat different if solvation effects are considered, since the formation of dimers and trimers is only favorable in the case of partially ionic silicates, i.e., in the case of the SNSI dimer and in the cases of the SN2SI, SNSISN and SISNSI trimers. As expected, the solvent, even treated in a very simple way, stabilizes the totally ionic silicates (with one negative charge per silicon atom) and the large positive enthalpies of condensation found in the gas-phase are largely reduced.

One can also analyze the evolution of the condensation enthalpy with the size of the silicate. In fully neutral condensation, the subsequent addition of $\mathrm{SN}$ units to the growing chain is thermodynamically favorable, alluding to the tendency for formation of long chains in neutral $\mathrm{pH}$ conditions (Iler, 1979). This can be seen by comparing the total enthalpy divided by the number of released water molecules, $\Delta H_{\text {cond }} / \mathrm{N}_{\text {water }}$, for $\mathrm{SN} 2, \mathrm{SN} 3, \mathrm{SN} 4$ and $\mathrm{SN} 5$. In solution, it is known that the condensation enthalpy of neutral silicate species tends to stabilize for very large polymers (Šefćík and McCormick, 1997). In our calculations, we observe a qualitatively similar effect:

$$
\begin{aligned}
& \mathrm{SN}+\mathrm{SN} \underset{\leftarrow}{\rightarrow} \mathrm{SN} 2+\mathrm{H}_{2} \mathrm{O} \quad \Delta H=-15.1 \mathrm{~kJ} / \mathrm{mol} \\
& \mathrm{SN} 2+\mathrm{SN} \underset{\leftarrow}{\longrightarrow} \mathrm{SN} 3+\mathrm{H}_{2} \mathrm{O} \quad \Delta H=-21.4 \mathrm{~kJ} / \mathrm{mol}
\end{aligned}
$$




$$
\begin{aligned}
& \mathrm{SN} 3+\mathrm{SN} \rightleftarrows \mathrm{SN} 4+\mathrm{H}_{2} \mathrm{O} \quad \Delta H=-32.9 \mathrm{~kJ} / \mathrm{mol} \\
& \mathrm{SN} 4+\mathrm{SN} \underset{\leftarrow}{\longrightarrow} \mathrm{SN} 5+\mathrm{H}_{2} \mathrm{O} \quad \Delta H=-30.1 \mathrm{~kJ} / \mathrm{mol}
\end{aligned}
$$

However, one must bear in mind that our calculations are restricted to relatively small oligomers optimized in the gas phase, and it is therefore difficult to compare them directly with silicate solution chemistry. If we now perform a similar analysis for condensation of fully charged oligomers (i.e., with one charge per silicon atom), we observe that the gas-phase condensation enthalpy per reaction becomes progressively more positive as the chain grows (compare $\Delta H_{\text {cond }} / \mathrm{N}_{\text {water }}$, for SI2, SI3, SI4 and SI5). In fact, successive additions of anionic monomers become thermodynamically unfavorable:

$$
\begin{aligned}
& \mathrm{SI}+\mathrm{SI} \underset{\leftarrow}{\rightarrow} \mathrm{SI} 2+\mathrm{H}_{2} \mathrm{O} \quad \Delta H=250.0 \mathrm{~kJ} / \mathrm{mol} \\
& \mathrm{SI} 2+\mathrm{SI}_{\leftarrow}^{\rightarrow} \mathrm{SI} 3+\mathrm{H}_{2} \mathrm{O} \quad \Delta H=424.0 \mathrm{~kJ} / \mathrm{mol} \\
& \mathrm{SI} 3+\mathrm{SI} \underset{\leftarrow}{\leftarrow} \mathrm{SI} 4+\mathrm{H}_{2} \mathrm{O} \quad \Delta H=564.8 \mathrm{~kJ} / \mathrm{mol} \\
& \mathrm{SI} 4+\mathrm{SI} \underset{\leftarrow}{\leftarrow} \mathrm{SI} 5+\mathrm{H}_{2} \mathrm{O} \quad \Delta H=682.1 \mathrm{~kJ} / \mathrm{mol}
\end{aligned}
$$

As explained previously, this trend is related to the increase of the negative charge density of larger oligomers, and suggests that formation of large highly charged silicate chains is troublesome, which is in line with experimental solution NMR (Knight, 1990; Knight and Kinrade, 
2002). It is also important to examine the propensity for cyclization. A neutral trimer, for example may either condense with another monomer to form a tetramer, or undergo an intramolecular condensation to yield an SN3_cyc. The enthalpies of these intramolecular condensation reactions are:

$$
\begin{array}{lll}
\mathrm{SN} 3 & \rightarrow \mathrm{SN} 3 \_ \text {cyc }+\mathrm{H}_{2} \mathrm{O} & \Delta H=29.2 \mathrm{~kJ} / \mathrm{mol} \\
\mathrm{SN} 4 \underset{\mathrm{SN}}{\leftarrow} \_ \text {cyc }+\mathrm{H}_{2} \mathrm{O} & \Delta H=33.4 \mathrm{~kJ} / \mathrm{mol}
\end{array}
$$

This means that cyclization of neutral silicates is unfavorable relative to linear condensation (see reactions 11 and 12). However, the energies are sufficiently low that formation of these cyclic species is thermodynamically possible, particularly if solvation effects are considered (the SCRF values for reactions 17 and 18 are $-5.9 \mathrm{~kJ} / \mathrm{mol}$ and $26.2 \mathrm{~kJ} / \mathrm{mol}$, respectively). If we now look at the formation of fully charged rings, an opposite conclusion may be drawn:

$$
\begin{array}{lll}
\text { SI3 } & \leftarrow \text { SI3_cyc }+\mathrm{H}_{2} \mathrm{O} & \Delta H=120.4 \mathrm{~kJ} / \mathrm{mol} \\
\mathrm{SI} 4 \underset{\mathrm{SI}}{\leftarrow} \_\mathrm{cyc}+\mathrm{H}_{2} \mathrm{O} & \Delta H=206.9 \mathrm{~kJ} / \mathrm{mol}
\end{array}
$$

since the enthalpies of reactions 19 and 20 are much lower than those of reactions 15 and 16 (even if solvation effects are considered). This indicates that highly charged silicates should show a preference for cyclic and cage-like structures. Once more, this is in line with observations from silicate solution NMR (Harris et al., 1981; Engelhardt and Hoebbel, 1983; Harris and Knight, 1983; 
Kinrade and Swaddle, 1988; Knight, 1990; Kinrade and Pole, 1992; Kinrade et al., 1998; Knight and Kinrade, 2002; Haouas and Taulelle, 2006).

\section{CONCLUSIONS}

This paper presents a detailed and systematic DFT study of small silicate oligomers (up to the pentamer) in vacuum. For each species, several charged states were considered, ranging from neutral molecules up to compounds with one negative charge per silicon atom. Many of these silicates are known to be present in precursor solutions that, given the right conditions (temperature, $\mathrm{pH}$, presence of appropriate template molecules, etc.), may produce zeolites and mesoporous silica materials. The complex nature of silicate chemistry means that these small oligomers already possess many degrees of freedom, which complicates the determination of the true energy minima on the potential energy surface. For that reason, we have considered several possible starting structures for each species, obtained either manually (e.g., for SI2, we have removed two protons from SN2 in all possible combinations) or from short molecular dynamics gas-phase trajectories. Furthermore, we have re-optimized the most stable structures (including several other almost degenerate geometries) using a large basis set, augmented by diffuse functions, in order to obtain reliable energy values for the ionic species. A comparison of different methods emphasizes the importance of including diffuse functions in the basis set, corroborating conclusions of previous studies.

In general, deprotonation of a silicate has a marked effect on its geometric parameters, shortening the Si-Oc bond, increasing the Si-Oh bonds, enlarging the Oc-Si-O angles and closing the Si-Oh-H angles. These changes are mainly the consequence of increased repulsions between oxygen atoms in anionic species. The trends presented above are consistently observed over a wide 
range of silicate species, thus corroborating a previous conclusion by Kubicki et al. $(1995,1996)$ that geometric effects of silicate deprotonation are virtually independent of molecular size. Our analysis of natural charges reveals that these are mostly determined by the charge per silicon in the molecule and by the degree of substitution of each silicon atom, with other effects being of minor importance. Therefore, each silicate may be envisioned in terms of individual connected fragments (one Si per fragment) with geometric parameters and point charges determined by the relative proportion and position of neutral and anionic units. These observations may be very useful for the development of a generic force field suitable for both neutral and anionic silicates. We intend to explore this possibility in future work.

When a neutral silicate undergoes its first deprotonation, the resulting single-charged species tends to adopt a configuration that optimizes the distribution of the negative charge along the molecule. For this reason, such species tend to be characterized by short hydrogen bonds involving deprotonated oxygens and by highly folded structures (e.g., SN3SI). As the polymer grows, this distribution of charge becomes easier, which causes the deprotonation enthalpy of neutral species to decrease with molecular size, and makes the enthalpy of formation of large single-charged species energetically less demanding. However, as successive deprotonations take place, increasing the overall charge density of the molecule, electrostatic repulsions between negatively charged units become dominant. These repulsions induce unfolding of the molecular scaffold (as in, e.g, the stretching of the SI5 chain), and cause deprotonated oxygens to point outwards without taking part in hydrogen bonds (e.g., SI3_cyc). A direct consequence of this is the increase in the mean deprotonation enthalpy per proton with molecular size for fully charged molecules, as well as the fact that condensation enthalpies become unfavorable for species with high charge density.

Our results show that silicate deprotonation has a negligible effect on the formation of branched structures in the gas phase, because the energies of deprotonation and condensation for branched silicates are very similar to those of their linear counterparts. However, deprotonation 
tends to have a pronounced effect on cyclization. Whereas the formation of neutral rings is slightly unfavorable compared to an extension of the linear chain, formation of highly charged cyclic structures is comparatively favorable. These and the above considerations suggest that highly charged silicates should tend to be as small and as condensed as possible, with a preference toward formation of rings and cages. Strictly speaking, these conclusions pertain only to gas-phase thermodynamics. Solvation of the intervening species in condensation and deprotonation reactions considered in a very simple way, i.e., single-point calculations within a SCRF approach on the gasphase optimized geometry, decreases drastically the magnitude of the enthalpies of condensation and deprotonation but the overall trends are maintained. It is likely that consideration of solvation with explicit water molecules will induce important changes in the molecular structures and, therefore, in the energetics of those reactions. We intend to study these effects in future work. Nevertheless, it is encouraging that our gas-phase results are in line with expectations based on NMR (Harris et al., 1981; Harris and Knight, 1983; Kinrade and Swaddle, 1988; Knight, 1990; Knight and Kinrade, 2002, Haouas and Taulelle, 2006), XRD (Martinez et al., 2006) and IR (Monsivais-Gamez et al., 2007) studies of silicate solutions.

Acknowledgements. J.R.B.G. thanks FCT and the European Social Fund (ESF), under the Community Support Framework (CSF), for the award of the grant with reference (SFRH/BPD/24676/2005). 


\section{References}

Auerbach S. M., Carrado K. A., Dutta P. K., editors (2003) Handbook of Zeolite Science and Technology, Dekker Inc.: New York.

Becke A. D. (1993) Density-functional thermochemistry. III. The role of exact-exchange. J. Chem. Phys. 98, 5648.

Berendsen H. J. C., van der Spoel D., van Drunen R. (1995) GROMACS - A message-passing parallel molecular-dynamics implementation. Comput. Phys. Commun. 91, 43.

Breneman C. M., Wiberg K. B. (1990) Determining atom-centered monopoles from molecular electrostatics potentials - The need for high sampling density in formamide conformational analysis. J. Comput. Chem. 11, 361.

Brinker C. J., Sherer G. W. (1990) Sol-gel Science: the Physics and Chemistry of Sol-gel Processing, Academic Press: San Diego.

Camps P., Domingo L. R., Formosa X., Galdeano C., González D., Muñoz-Torrero D., Segalés S., Font-Bardia M., Solans X. (2006) Highly diastereoselective one-pot synthesis of spiro $\{$ cyclopenta $[a]$ indene-2,2'-indene $\}$ diones from 1 -indanones and aromatic aldehydes. $J$. Org. Chem. 71, 3464.

Carlson H. A., Nguyen T. B., Orozco M., Jorgensen W. L. (1993) Accuracy of free-energies of hydration for organic-molecules from 6-31G*-derived partial charges. J. Comput. Chem. 14, 1240.

Crerar D. A., Axtmann E. V., Axtmann R. C. (1981) Growth and ripening of silica polymers in aqueous solutions. Geochim. Cosmochim. Acta, 45, 1259.

Davis M. E., Lobo R. F. (1992) Zeolite and molecular sieve synthesis. Chem. Mater. 4, 756.

Durig, J. R., Flanagan, M. J., Kalasinsky, V. F. (1977) Determination of potential function 
governing low-frequency bending mode of disiloxane. J. Chem. Phys. 66, 2775.

Engelhardt G., Hoebbel D. (1983) On the temperature-dependence of the distribution of silicate anions in aqueous tetraalkylammonium-silicate solutions. Z. Chem. 23, 33.

Felmy A. R., Cho H., Rustad J. R., Mason M. J. (2001) An aqueous thermodynamic model for polymerized silica species to high ionic strength. J. Sol. Chem. 30, 509.

Ferraz R., Gomes J. R. B., de Oliveira E., Moreira R., Gomes P. (2007) Unanticipated stereoselectivity in the reaction of primaquine $\alpha$-aminoamides with substituted benzaldehydes: A computational and experimental Study J. Org. Chem. 72, 4189.

Firouzi A., Atef F., Oertli A. G., Stucky G. D., Chmelka B. F.(1997) Alkaline Lyotropic SilicateSurfactant Liquid Crystals. J. Am. Chem. Soc. 119, 3596.

Florin A. E., Alei M. (1967) ${ }^{17} \mathrm{O}$ NMR shifts in $\mathrm{H}_{2}{ }^{17} \mathrm{O}$ liquid and vapor. J. Chem. Phys. 47, 4268.

Frisch M. J., Trucks G. W., Schlegel H. B., Scuseria G. E., Robb M. A., Cheeseman J. R., Montgomery Jr. J. A., Vreven T., Kudin K. N., Burant J. C., Millam J. M., Iyengar S. S., Tomasi J., Barone V., Mennucci B., Cossi M., Scalmani G., Rega N., Petersson G. A., Nakatsuji H., Hada M., Ehara M., Toyota K., Fukuda R., Hasegawa J., Ishida M., Nakajima T., Honda Y., Kitao O., Nakai H., Klene M., Li X., Knox J. E., Hratchian H. P., Cross J. B., Bakken V., Adamo C., Jaramillo J., Gomperts R., Stratmann R. E., Yazyev O., Austin A. J., Cammi R., Pomelli C., Ochterski J. W., Ayala P. Y., Morokuma K., Voth G. A., Salvador P., Dannenberg J. J., Zakrzewski V. G., Dapprich S., Daniels A. D., Strain M. C., Farkas O., Malick D. K., Rabuck A. D., Raghavachari K., Foresman J. B., Ortiz J. V., Cui Q., Baboul A. G., Clifford S., Cioslowski J., Stefanov B. B., Liu G., Liashenko A., Piskorz P., Komaromi I., Martin R. L., Fox D. J., Keith T., Al-Laham M. A., Peng C. Y., Nanayakkara A., Challacombe M., Gill P. M. W., Johnson B., Chen W., Wong M. W., Gonzalez C., and Pople J. A. (2004) Gaussian 03, Revision C.01, Gaussian, Inc., Wallingford CT. 
Gomes J. R. B., Ribeiro da Silva M. A. V. (2004) Thermochemistry of small organosulfur compounds from ab initio calculations. J. Phys. Chem. A 108, 11684.

Gomes J. R. B., Ribeiro da Silva M. A. V. (2005) Density functional theory study on the thermodynamic properties of aminophenols. Int. J. Quant. Chem. 101, 860.

Gomes J. R. B., Ribeiro da Silva M. A. V. (2006) Computational study on the bond dissociation enthalpies in the enolic and ketonic forms of $\beta$-diketones: Their influence on metal-ligand bond enthalpies J. Phys. Chem. A 110, 13948.

Gomes P., Gomes J. R. B., Rodrigues M., Moreira R. (2003) Amino acids as selective sulfonamide acylating agents. Tetrahedron, 59, 7473.

Haouas M., Taulelle F. (2006) Revisiting the identification of structural units in aqueous silicate solutions by two-dimensional silicon-29 INADEQUATE. J. Phys. Chem. B 110, 3007.

Harris R. K., Knight C. T. G. (1983) Silicon-29 nuclear magnetic resonance studies of aqueous silicate solutions: 5. First-order patterns in potassium silicate solutions enriched with silicon29. J. Chem. Soc., Faraday Trans. 79, 1525.

Harris R. K., Knight C. T. G., Hull W. E. (1981) Nature of species present in an aqueous solution of potassium silicate. J. Am. Chem. Soc. 103, 1577.

Hill J.-R., Sauer J. (1994) Molecular mechanics potential for silica and zeolite catalysts based on ab initio calculations. 1. Dense and microporous silica. J. Phys. Chem. 98, 1238.

Houssin C. J. Y., Kirschhock C. E. A., Magussin P. C. M. M., Mojet B. L., Grobet P. J., Jacobs P. A., Martens J. A., van Santen R. A. (2003) Combined in situ Si NMR and small-angle x-ray scattering study of precursors in MFI zeolite formation from silicic acid in TPAOH solutions. Phys. Chem. Chem. Phys. 5, 3518.

Iler R. K. (1979) The Chemistry of Silica, John Wiley \& Sons: New York.

Jorge M., Gomes J. R. B., Cordeiro M. N. D. S., Seaton N. (2007) Molecular simulation of 
silica/surfactant self-assembly in the synthesis of periodic mesoporous silicas. J. Am. Chem. Soc. 129, 15414.

Kinrade S. D., Knight C. T. G., Pole D. T., Syvitski R. T. (1998) Silicon-29 NMR studies of tetraalkylammonium silicate solutions. 1. Equilibria, ${ }^{29} \mathrm{Si}$ chemical shifts, and ${ }^{29} \mathrm{Si}$ relaxation. Inorg. Chem. 37, 4272.

Kinrade S. D., Pole D. L. (1992) Effect of alkali-metal cations on the chemistry of aqueous silicate solutions. Inorg. Chem. 31, 4558.

Kinrade S. D., Swaddle T. W. (1988) Silicon-29 NMR studies of aqueous silicate solutions 1. Chemical shifts and equilibria. Inorg. Chem. 27, 4253.

Kirschhock C. E. A., Ravishankar R., Verspeurt F., Grobet P. J., Jacobs P. A., Martens J. A. (1999) Identification of precursor species in the formation of MFI zeolite in the TPAOH-TEOS- $\mathrm{H}_{2} \mathrm{O}$ system J. Phys. Chem. B 103, 4965.

Knight C. T. G. (1990) Are zeolite secondary building units really red herrings?. Zeolites 10, 140.

Knight C. T. G., Kinrade S. D. (2002) Comment on "Identification of precursor species in the formation of MFI zeolite in the TPAOH-TEOS- $\mathrm{H}_{2} \mathrm{O}$ system”. J. Phys. Chem. B 106, 3329.

Knight C. T. G., Wang J., Kinrade S. D. (2006) Do zeolite precursor species really exist in aqueous synthesis media?. Phys. Chem. Chem. Phys. 8, 3099.

Kubicki J. D. (2001) Self-consistent reaction field calculations of aqueous $\mathrm{Al}^{3+}, \mathrm{Fe}^{3+}$, and $\mathrm{Si}^{4+}$ : Calculated aqueous-phase deprotonation energies correlated with experimental $\ln \left(K_{\mathrm{a}}\right)$ and $\mathrm{p} K_{\mathrm{a}}$. J. Phys. Chem. A, 105, 8756.

Kubicki J. D., Apitz S. E., Blake G. A. (1995) G2 theory calculations on $\left[\mathrm{H}_{3} \mathrm{SiO}_{4}\right]^{-},\left[\mathrm{H}_{4} \mathrm{SiO}_{4}\right]$, $\left[\mathrm{H}_{3} \mathrm{AlO}_{4}\right]^{2-},\left[\mathrm{H}_{4} \mathrm{AlO}_{4}\right]^{-}$and $\left[\mathrm{H}_{5} \mathrm{AlO}_{4}\right]$ : Basis sets and electron correlation effects on molecular structures, atomic charges, infrared spectra, and potential energies. Phys. Chem. Minerals 22, 481. 
Kubicki J. D., Blake G. A., Apitz S. E. (1996) Ab initio calculations on aluminosilicate $Q^{3}$ species: Implications for anionic structures of mineral surfaces and dissolution mechanisms of feldspars. American Mineralogist 81, 789.

Kubicki J. D., Sykes D. (1993) Molecular orbital calculations on $\mathrm{H}_{6} \mathrm{Si}_{2} \mathrm{O}_{7}$ with a variable Si-O-Si angle: Implications for the high-pressure vibrational spectra of silicate glasses. American Mineralogist 78, 253

Lee C., Yang W., Parr R. G. (1988) Development of the Colle-Salvetti correlation-energy formula into a functional of the electron density. Phys. Rev. B. 37, 785.

Lindahl E., Hess B., van der Spoel D. (2001) GROMACS 3.0: a package for molecular simulation and trajectory analysis. J. Mol. Mod. 7, 306

Lippmaa E., Magi M., Samoson A., Engelhardt G., Grimmer A. R. (1980) Structural studies of silicates by solid-state high-resolution silicon-29 NMR J. Am. Chem. Soc. 102, 4889.

Martínez J. R., Palomares-Sánchez S., Ortega-Zarzosa G., Ruiz F., Chumakov Y. (2006) Rietveld refinement of amorphous $\mathrm{SiO} 2$ prepared via sol-gel method. Mater. Lett. 60, 3526.

Monsivais-Gámez E., Ruiz F., Martínez J. R. (2007) Four-membered rings family in the Si-O extended rocking IR band from quantum chemistry calculations J. Sol-Gel Sci. Technol. 43, 65.

Mora-Fonz M. J., Catlow C. R. A., Lewis D. W. (2005) Oligomerization and cyclization processes in the nucleation of microporous silicas. Angew. Chem. Int. Ed. 44, 3082.

Moravetski V., Hill J.-R., Eichler U., Cheetham A. K., Sauer, J. (1996) ${ }^{29}$ Si NMR chemical shifts of silicate species: Ab initio study of environment and structure effects. J. Am. Chem. Soc., 118, 13015.

Mulliken, R. S. (1995) Electronic population analysis on LCAO-MO molecular wave functions. 1. $J$. Chem. Phys. 23, 1833.

Murashov V. (2003) Ab initio cluster calculations of silica surface sites. J. Mol. Struct. 650, 141. 
Pereira J. C. G., Catlow C. R. A., Price G. D. (1999a) Ab initio studies of silica-based clusters. Part I. Energies and conformations of simple clusters. J. Phys. Chem. A 103, 3252.

Pereira J. C. G., Catlow C. R. A., Price G. D. (1999b) Ab initio studies of silica-based clusters. Part II. Structures and energies of complex clusters. J. Phys. Chem. A 103, 3268.

Pereira J. C. G., Catlow C. R. A., Price G. D. (2002) Molecular dynamics simulation of methanolic and ethanolic silica-based sol-gel solutions at ambient temperature and pressure. J. Phys. Chem. A 106, 130.

Reed A. E., Weinstock R. B., Weinhold F. A. (1985) Natural-population analysis. J. Chem. Phys. 83, 735 .

Rustad J. R., Dixon D. A., Kubicki J. D., Felmy A. R. (2000) Gas-phase acidities of tetrahedral oxyacids from ab initio electronic structure theory. J. Phys. Chem. A 104, 4051.

Šefč́́k J., Goddard III W. A. (2001) Thermochemistry of silicic acid deprotonation: Comparison of gas-phase and solvated DFT calculations to experiment. Geochim. Cosmochim. Acta 65, 4435.

Šefčík J., McCormick A. V. (1997) Thermochemistry of aqueous silicate solution precursors to ceramics. AIChE J. 43, 2773.

Sigfridsson E., Ryde U. (1998) Comparison of methods for deriving atomic charges from the electrostatic potential and moments. J. Comput. Chem. 19, 377.

Teppen B. J., Miller D. M., Newton S. Q., Schäfer L. (1994) Choice of computational techniques and molecular models for ab initio calculations pertaining to solid silicates. J. Phys. Chem. 98, 12545.

Tossell J. A., Sahai N. (2000) Calculating the acidity of silanols and related oxyacids in aqueous solution. Geochim. Cosmochim. Acta 64, 4097.

Trinh T. T., Jansen A. P. J., van Santen R. A. (2006) Mechanism of oligomerization reactions of silica. J. Phys. Chem. B, 110, 23099. 
Unger B., Jancke H., Hähnert M., Stade H. (1994) The early stages of the sol-gel processing of TEOS. J. Sol-Gel Sci. Technol. $2,51$.

Vosko S. J., Wilk L., Nusair M. (1980) Accurate spin-dependent electron liquid correlation energies for local spin-density calculations - A critical analysis. Can J. Phys. 58, 1200.

Xiao Y., Lasaga A. C. (1996) Ab initio quantum mechanical studies of the kinetics and mechanisms of quartz dissolution: $\mathrm{OH}^{-}$catalysis. Geochim. Cosmochim. Acta 60, 2283.

Xu S., Park S. T., Feenstra J. S., Srinivasan R., Zewail A. H. (2004) Ultrafast electron diffraction: Structural dynamics of the elimination reaction of acetylacetone $J$. Phys. Chem. A 108, 6650 . 
Table 1 - Average and standard deviations of bond lengths for all silicates studied.

\begin{tabular}{c|cc} 
Bond & Average $(\AA)$ & Standard Deviation $(\AA)$ \\
\hline $\mathrm{Si}_{\mathrm{N}}-\mathrm{Oh}_{\mathrm{N}}$ & 1.6394 & 0.0040 \\
$\mathrm{Si}_{\mathrm{I}}-\mathrm{Oh}_{\mathrm{I}}$ & 1.6887 & 0.0238 \\
$\mathrm{Oh}_{\mathrm{N}}-\mathrm{H}_{\mathrm{N}}$ & 0.9694 & 0.0093 \\
$\mathrm{Oh}_{\mathrm{I}}-\mathrm{H}_{\mathrm{I}}$ & 0.9658 & 0.0092 \\
$\mathrm{Si}_{\mathrm{I}}-\mathrm{Oc}$ & 1.5770 & 0.0124 \\
$\mathrm{Si}_{\mathrm{N}}-\mathrm{Ob}_{\mathrm{NN}}$ & 1.6372 & 0.0072 \\
$\mathrm{Si}_{\mathrm{N}}-\mathrm{Ob}_{\mathrm{NI}}$ & 1.6330 & 0.0093 \\
$\mathrm{Si}_{\mathrm{I}}-\mathrm{Ob}_{\mathrm{NI}}$ & 1.6719 & 0.0165 \\
$\mathrm{Si}_{\mathrm{I}}-\mathrm{Ob}_{\mathrm{II}}$ & 1.6780 & 0.0090
\end{tabular}


Table 2 - Average and standard deviations of bond angles for all silicates studied.

\begin{tabular}{c|cc} 
Angle & Average $(\AA)$ & Standard Deviation $(\AA)$ \\
\hline $\mathrm{Si}_{\mathrm{N}}-\mathrm{Oh}_{\mathrm{N}}-\mathrm{H}_{\mathrm{N}}$ & 114.4 & 2.5 \\
$\mathrm{Si}_{\mathrm{I}}-\mathrm{Oh}_{\mathrm{I}}-\mathrm{H}_{\mathrm{I}}$ & 109.8 & 2.7 \\
$\mathrm{Oh}_{\mathrm{N}}-\mathrm{Si}_{\mathrm{N}}-\mathrm{Oh}_{\mathrm{N}}$ & 109.4 & 1.6 \\
$\mathrm{Oh}_{\mathrm{N}}-\mathrm{Si}_{\mathrm{N}}-\mathrm{Ob}_{\mathrm{NN}}$ & 109.3 & 0.6 \\
$\mathrm{Oh}_{\mathrm{N}}-\mathrm{Si}_{\mathrm{N}}-\mathrm{Ob}_{\mathrm{NI}}$ & 109.7 & 1.3 \\
$\mathrm{Ob}_{\mathrm{NN}}-\mathrm{Si}_{\mathrm{N}}-\mathrm{Ob}_{\mathrm{NN}}$ & 109.3 & 1.6 \\
$\mathrm{Ob}_{\mathrm{NN}}-\mathrm{Si}_{\mathrm{N}}-\mathrm{Ob}_{\mathrm{NI}}$ & 110.9 & 1.7 \\
$\mathrm{Ob}_{\mathrm{NI}}-\mathrm{Si}_{\mathrm{N}}-\mathrm{Ob}_{\mathrm{NI}}$ & 109.9 & 0.6 \\
$\mathrm{Oh}_{\mathrm{I}}-\mathrm{Si}_{\mathrm{I}}-\mathrm{Oh}_{\mathrm{I}}$ & 104.9 & 2.0 \\
$\mathrm{Oh}_{\mathrm{I}}-\mathrm{Si}_{\mathrm{I}}-\mathrm{Ob}_{\mathrm{II}}$ & 102.7 & 0.4 \\
$\mathrm{Oh}_{\mathrm{I}}-\mathrm{Si}_{\mathrm{I}}-\mathrm{Ob}_{\mathrm{NI}}$ & 104.3 & 1.7 \\
$\mathrm{Ob}_{\mathrm{II}}-\mathrm{Si}_{\mathrm{I}}-\mathrm{Ob}_{\mathrm{II}}$ & 107.9 & 2.1 \\
$\mathrm{Ob}_{\mathrm{NI}}-\mathrm{Si}_{\mathrm{I}}-\mathrm{Ob}_{\mathrm{NI}}$ & 105.4 & 3.0 \\
$\mathrm{Oc}_{-}-\mathrm{Si}_{\mathrm{I}}-\mathrm{Oh}_{\mathrm{I}}$ & 114.3 & 1.4 \\
$\mathrm{Oc}_{-}-\mathrm{Si}_{\mathrm{I}}-\mathrm{Ob}_{\mathrm{II}}$ & 115.8 & 1.7 \\
$\mathrm{Oc}_{-}-\mathrm{Si}_{\mathrm{I}}-\mathrm{Ob}_{\mathrm{NI}}$ & 113.2 & 2.7 \\
$\mathrm{Si}_{\mathrm{N}}-\mathrm{Ob}_{\mathrm{NN}}-\mathrm{Si}_{\mathrm{N}}$ & 135.9 & 6.7 \\
$\mathrm{Si}_{\mathrm{N}}-\mathrm{Ob}_{\mathrm{NI}}-\mathrm{Si}_{\mathrm{I}}$ & 131.5 & 10.1 \\
$\mathrm{Si}_{\mathrm{I}}-\mathrm{Ob}_{\mathrm{II}}-\mathrm{Si}_{\mathrm{I}}$ & 130.3 & 4.4
\end{tabular}


Table 3 - Atomic charges for the monomers in a.u..

\begin{tabular}{|c|c|c|c|c|c|c|}
\hline \multirow[b]{2}{*}{$\operatorname{Atom}^{a}$} & \multicolumn{3}{|c|}{$\mathrm{Si}(\mathrm{OH})_{4}$} & \multicolumn{3}{|c|}{$\left[\mathrm{Si}(\mathrm{OH})_{3} \mathrm{O}^{-}\right.$} \\
\hline & Mulliken & CHelpG & $\overline{\text { NPA }}$ & Mulliken & CHelpG & $\overline{\text { NPA }}$ \\
\hline $\mathbf{S i}$ & 2.082 & 1.418 & 2.380 & 1.816 & 1.428 & 2.292 \\
\hline Oh & -0.790 & -0.799 & -1.094 & -0.813 & -0.761 & -1.113 \\
\hline Oc & - & - & - & -1.082 & -1.065 & -1.356 \\
\hline H & 0.269 & 0.444 & 0.499 & 0.235 & 0.307 & 0.467 \\
\hline
\end{tabular}

${ }^{\text {a }}$ Oh stands for an oxygen atom in a hydroxyl group, while Oc stands for a deprotonated oxygen atom (see text). 
Table 4 - Atomic charges for the dimers in a.u.. ${ }^{a}$

\begin{tabular}{c|c|c|c|c|c|c|} 
& \multicolumn{2}{|c|}{$(\mathbf{O H})_{3} \operatorname{SiOSi}(\mathbf{O H})_{3}$} & \multicolumn{2}{c|}{$\left[(\mathbf{O H})_{3} \operatorname{SiOSi}(\mathbf{O H})_{2} \mathbf{O}^{-}\right.$} & \multicolumn{2}{c|}{$\left[\mathbf{O}(\mathbf{O H})_{2} \mathbf{S i O S i}(\mathbf{O H})_{2} \mathbf{O}^{2-}\right.$} \\
\cline { 2 - 7 } $\mathbf{A t o m}^{\mathrm{b}}$ & $\mathbf{C H e l p G}$ & $\mathbf{N P A}$ & $\mathbf{C H e l p G}$ & $\mathbf{N P A}$ & CHelpG & $\mathbf{N P A}$ \\
\hline $\mathbf{S i}_{\mathbf{N}}$ & 1.381 & 2.409 & 1.297 & 2.401 & - & - \\
$\mathbf{S i}_{\mathbf{I}}$ & - & - & 1.313 & 2.342 & 1.760 & 2.339 \\
$\mathbf{O h}_{\mathbf{N}}$ & $-0.716 ;-0.818$ & $-1.085 ;-1.107$ & $-0.693 ;-0.824$ & $-1.096 ;-1.172$ & - & - \\
$\mathbf{O h}_{\mathbf{I}}$ & - & - & $-0.713 ;-0.758$ & $-1.100 ;-1.102$ & $-0.869 ;-0.995$ & $-1.140 ;-1.144$ \\
$\mathbf{O c}$ & - & - & -0.993 & -1.337 & -1.128 & -1.363 \\
$\mathbf{O b}$ & -0.692 & -1.265 & -0.693 & -1.282 & -1.037 & -1.307 \\
$\mathbf{H}$ & $0.416 ; 0.451$ & $0.501 ; 0.511$ & $0.323 ; 0.428$ & $0.472 ; 0.534$ & $0.302 ; 0.448$ & $0.466 ; 0.496$
\end{tabular}

${ }^{\mathrm{a}}$ Where more than one value exists, the highest and lowest charges are shown.

${ }^{\mathrm{b}}$ Labels used are: $\mathrm{Si}$ is a silicon atom, $\mathrm{H}$ is a hydrogen atom, $\mathrm{Oh}$ is an oxygen atom in a hydroxyl group, $\mathrm{Oc}$ is a deprotonated oxygen atom and $\mathrm{Ob}$ is a bridging oxygen atom; subscripts $\mathrm{N}$ and I are for atoms belonging to neutral or ionic fragments, respectively. 
Table 5 - Gas-phase enthalpies of deprotonation and condensation in $\mathrm{kJ} / \mathrm{mol}$ at $T=298.15 \mathrm{~K}$. Values calculated within a SCRF approach are given inside parenthesis (see text).

\begin{tabular}{|l|c|c|c|c|}
\hline Molecule & $\Delta \boldsymbol{H}_{\text {dep }}{ }^{\mathbf{a}}$ & $\Delta \boldsymbol{H}_{\text {dep }} / \boldsymbol{n}^{\mathbf{b}}$ & $\Delta \boldsymbol{H}_{\text {cond }}{ }^{\mathbf{c}}$ & $\Delta \boldsymbol{H}_{\text {cond }} / \mathbf{N}_{\text {water }}{ }^{\mathbf{d}}$ \\
\hline SI & $1473.7(226.0)$ & $1473.7(226.0)$ & & \\
\hline SN2 & & & $-15.1(18.4)$ & $-15.1(18.4)$ \\
\hline SNSI & $1402.1(194.4)$ & $1402.1(194.4)$ & $-86.7(-13.1)$ & $-86.7(-13.1)$ \\
\hline SI2 & $3212.5(450.1)$ & $1606.3(225.1)$ & $250.0(16.6)$ & $250.0(16.6)$ \\
\hline SN3 & & $-36.4(12.4)$ & $-18.2(6.2)$ \\
\hline SN2SI & $1353.7(202.9)$ & $1353.7(202.9)$ & $-156.5(-10.6)$ & $-78.2(-5.3)$ \\
\hline SNSISN & $1355.1(208.4)$ & $1355.1(208.4)$ & $-155.1(-5.1)$ & $-77.5(-2.6)$ \\
\hline SISNSI & $3070.9(417.3)$ & $1535.5(208.7)$ & $87.0(-22.2)$ & $43.5(-11.1)$ \\
\hline SI3 & $5131.6(692.4)$ & $1710.5(230.8)$ & $674.0(26.9)$ & $337.0(13.4)$ \\
\hline SN3_cyc & & & $-7.2(6.6)$ & $-2.4(2.2)$ \\
\hline SN2SI_cyc & $1412.3(230.6)$ & $1412.3(230.6)$ & $-68.6(11.2)$ & $-22.9(3.7)$ \\
\hline SI3_cyc & $5222.7(708.5)$ & $1740.9(236.2)$ & $794.4(37.2)$ & $264.8(12.4)$ \\
\hline SN4 & & & $-69.3(25.4)$ & $-23.1(8.5)$ \\
\hline SN3SI & $1316.9(166.7)$ & $1316.9(166.7)$ & $-226.1(-33.9)$ & $-75.4(-11.3)$ \\
\hline SN2SISN & $1330.6(181.2)$ & $1330.6(181.2)$ & $-212.4(-19.4)$ & $-70.8(-6.5)$ \\
\hline SI4 & $7203.0(903.6)$ & $1800.8(225.9)$ & $1238.9(25.0)$ & $413.0(8.3)$ \\
\hline SN4_cyc & & & $-35.9(51.6)$ & $-9.0(12.9)$ \\
\hline SI4_cyc & $7387.1(883.4)$ & $1846.8(220.9)$ & $1456.3(31.1)$ & $364.1(7.8)$ \\
\hline (SN)-3SN & & & $-68.3(23.5)$ & $-22.8(7.8)$ \\
\hline (SN)-2SN,SI & $1331.0(181.1)$ & $1331.0(181.1)$ & $-210.9(-21.4)$ & $-70.3(-7.1)$ \\
\hline (SI)-3SN & $1326.5(181.5)$ & $1326.5(181.5)$ & $-215.4(-21.0)$ & $-71.8(-7.0)$ \\
\hline (SI)-3SI & $7232.4(909.7)$ & $1808.1(227.4)$ & $1269.3(29.3)$ & $423.1(9.8)$ \\
\hline (SN)-SN3_cyc & & & $-46.7(19.1)$ & $-11.7(4.8)$ \\
\hline (SI)-SN3_cyc & $1331.9(178.4)$ & $1331.9(178.4)$ & $-188.5(-28.5)$ & $-47.1(-7.1)$ \\
\hline SN5 & & & $-99.4(26.3)$ & $-24.9(6.6)$ \\
\hline SN4SI & $1300.5(176.9)$ & $1300.5(176.9)$ & $-272.7(-22.8)$ & $-68.2(-5.7)$ \\
\hline SN3SISN & $1305.5(185.0)$ & $1305.5(185.0)$ & $-267.6(-14.7)$ & $-66.9(-3.7)$ \\
\hline SN2SISN2 & $1321.4(186.0)$ & $1321.4(186.0)$ & $-251.7(-13.7)$ & $-62.9(-3.4)$ \\
\hline SI5 & $9389.0(1150.8)$ & $1877.8(230.2)$ & $1921.0(47.2)$ & $480.3(11.8)$ \\
\hline (SN)-4SN & & & $-82.3(24.2)$ & $-20.6(6.1)$ \\
\hline (SN)-3SN,SI & $1304.9(205.7)$ & $1304.9(205.7)$ & $-251.1(3.9)$ & $-62.8(1.0)$ \\
\hline (SN)-4SI & $7083.9(931.0)$ & $1771.0(232.7)$ & $1106.7(51.3)$ & $276.7(12.8)$ \\
\hline DeprOtonatin & & & & \\
\hline
\end{tabular}

${ }^{\mathrm{a}}$ Deprotonation enthalpy calculated from the parent neutral species as $H\left(\mathrm{SN}_{\mathrm{x}-\mathrm{n}} \mathrm{SI}_{\mathrm{n}}\right)+n H\left(\mathrm{H}^{+}\right)-$ $H\left(\mathrm{SN}_{\mathrm{x}}\right)$, where $x$ varies from 1 to 5 and $n \leq x$ (i.e., eq. 4 with $y=0$ ).

${ }^{b}$ Deprotonation enthalpy divided by the number of negative charges in the anionic silicates $(n)$.

${ }^{c}$ Enthalpy of condensation calculated according to eq. 7 for linear and branched silicates or eq. 8 for cyclic silicates.

${ }^{\mathrm{d}}$ Enthalpy of condensation divided by the number of water molecules released in the condensation reaction. 
Table 6 - Gas-phase deprotonation enthalpy of the SN species in $\mathrm{kJ} / \mathrm{mol}$ calculated with several different computational approaches, at $T=298.15 \mathrm{~K}^{\mathrm{a}}$

\begin{tabular}{|c|c|c|c|c|}
\hline & Reference & $\Delta H_{\mathrm{R}}(\mathbf{4}){ }^{\mathrm{b}}$ & $\Delta H_{\mathrm{R}}(\mathbf{5})^{\mathrm{c}}$ & $\Delta G_{R}(\mathbf{5})^{d}$ \\
\hline B3LYP/6-311+G(2d,2p) & This work & $1473.7(1467.7)$ & $-158.8(-159.9)$ & $-165.0[-168.0]$ \\
\hline B3LYP/6-31G(d,p) & This work & 1522.8 & -267.6 & $-273.6[-276.5]$ \\
\hline B3LYP/6-31+G(d,p)//B3LYP/6-31G(d,p) ${ }^{\mathrm{e}}$ & This work & 1466.4 & -154.4 & $-165.3[-168.1]$ \\
\hline BLYP/6-31G(d,p) & This work & 1511.6 & -281.9 & $-288.0[-291.0]$ \\
\hline BLYP/6-31+G(d,p)//BLYP/6-31G(d,p) ${ }^{e}$ & This work & 1447.7 & -161.0 & $-167.1[-170.1]$ \\
\hline B3LYP/6-31+G(d,p) & Murashov, 2003 & $(1459.5)$ & $(-162.2)$ & - \\
\hline B3LYP/6-311++G(d,p) & Rustad et al., 2000 & $(1463.6)$ & - & - \\
\hline G2 & Kubicki et al, 1995 & 1471.0 & - & - \\
\hline B3LYP/6-31G(d,p) & Šefč́ík and Goddard III, 2001 & 1523.0 & - & - \\
\hline B3LYP/6-31+G(d,p)//B3LYP/6-31G(d,p) ${ }^{\mathrm{e}}$ & Šefč́ík and Goddard III, 2001 & $1467.1(1461.6)$ & -158.4 & -161.8 \\
\hline BLYP/DNP & Mora-Fonz et al., 2005 & - & - & {$[-229]$} \\
\hline
\end{tabular}

${ }^{a}$ Values inside parenthesis correspond to $T=0 \mathrm{~K}$; Values inside square brackets correspond to $T=450 \mathrm{~K}$.

${ }^{\mathrm{b}}$ Computed enthalpy of the reaction shown in equation (4).

${ }^{\mathrm{c} C}$ Computed enthalpy of the reaction shown in equation (5).

${ }^{\mathrm{d} C}$ Computed Gibbs free energy of the reaction shown in equation (5).

${ }^{\text {e}}$ Single-point calculation using the $6-31+\mathrm{G}(\mathrm{d}, \mathrm{p})$ basis set on the geometry optimized with the $6-31 \mathrm{G}(\mathrm{d}, \mathrm{p})$ basis set. 


\section{Figure captions}

Figure 1 - Geometries for the monomers. Bond lengths are in $\AA$ and bond angles are in degrees.

Figure 2 - Geometries for the dimers. Bond lengths are in $\AA$ and bond angles are in degrees.

Figure 3 - Geometries for the trimers. Bond lengths are in $\AA$ and bond angles are in degrees.

Figure 4 - Geometries for the tetramers. Bond lengths are in $\AA$ and bond angles are in degrees.

Figure 5 - Geometries for the pentamers. Bond lengths are in $\AA$ and bond angles are in degrees.

Figure 6 - Net charge on neutral (SN) and anionic (SI) fragments for all silicates, plotted as a function of charge per silicon atom in the molecule. Lines are linear fits to the data. Note that some of the fragments may belong to the same molecule.

Figure 7 - Net charge on hydroxyl groups belonging to SN or SI fragments, plotted as a function of charge per silicon atom in the molecule. The line is a linear fit to the entire data set.

Figure 8 - Point charge on silicon atoms belonging to neutral or anionic fragments, plotted as a function of degree of substitution of the Si atom. Lines are linear fits to the data.

Figure 9 - Variation of the deprotonation enthalpy of linear (a) $\mathrm{SI}_{y}$ and (b) $\mathrm{SN}_{x} \mathrm{SI}$ silicates with the size of the polymeric chain; $y$ may assume integers 1 to 5 while $x$ varies between 1 and 4 . The lines are a guide to the eye. 


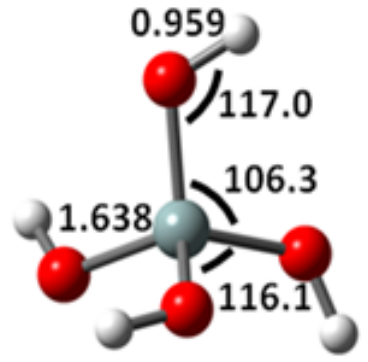

SN

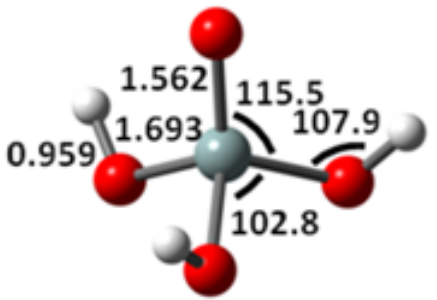

SI

Figure 1 


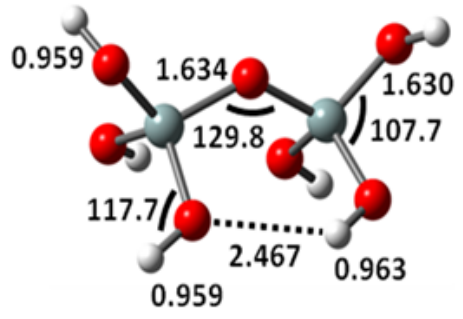

SN2

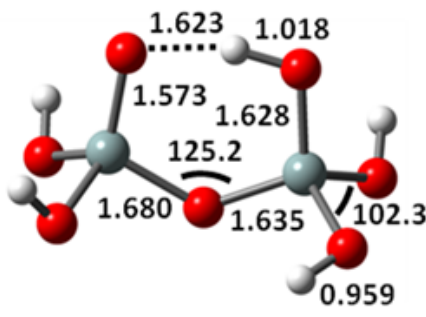

SNSI

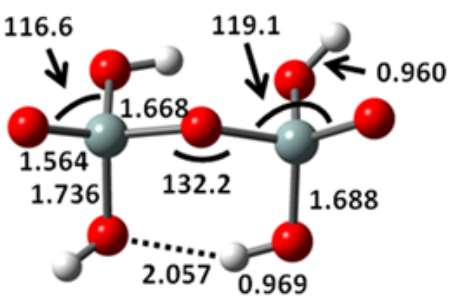

SI2

Figure 2 


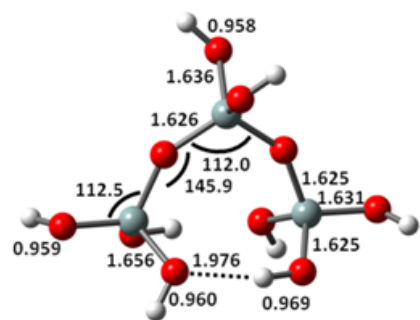

SN3

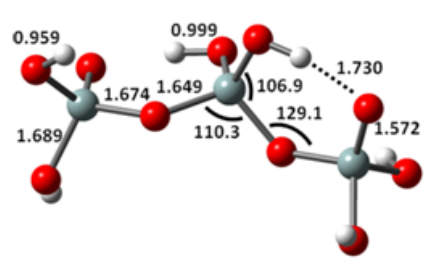

SISNSI

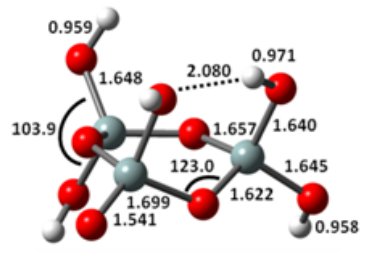

SN2SI_cyc

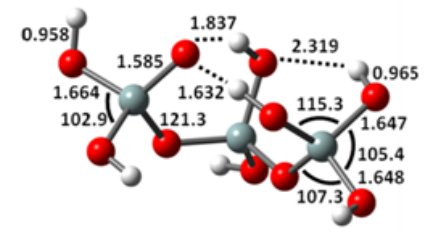

SN2SI

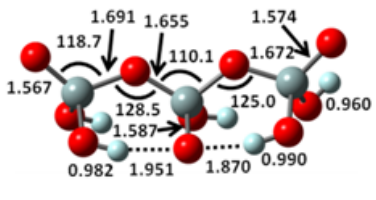

SI3

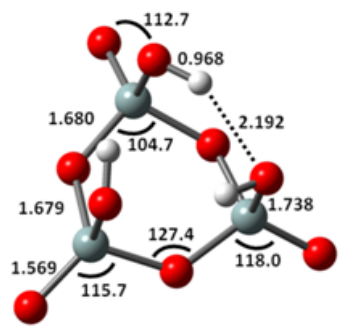

SI3_cyc

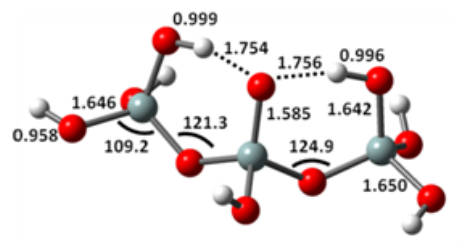

SNSISN

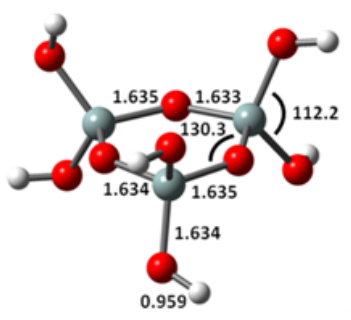

SN3_cyc

Figure 3 


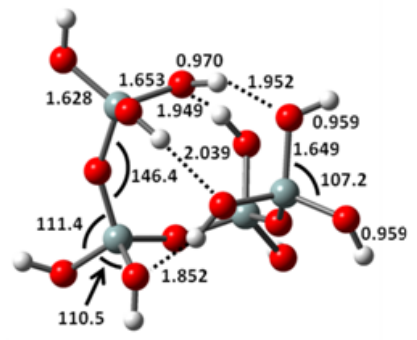

SN4

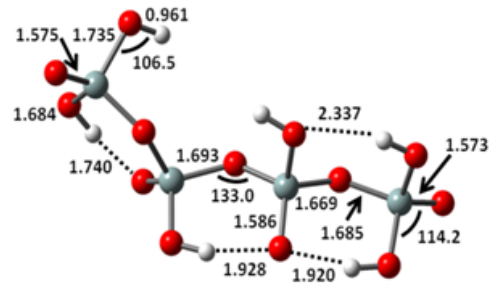

SI4

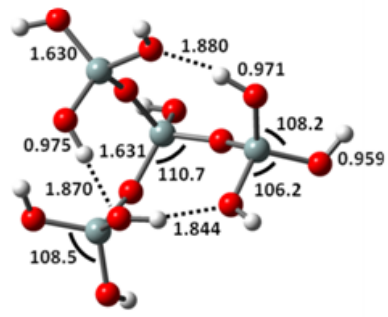

(SN)-3SN

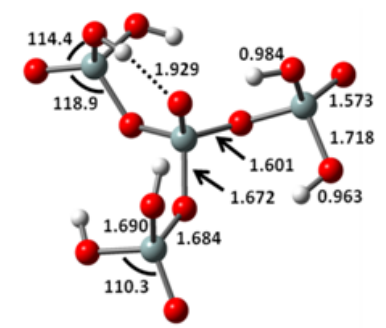

(SI)-3SI

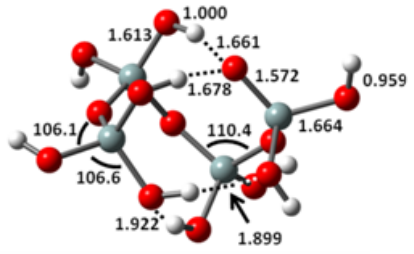

SN3SI

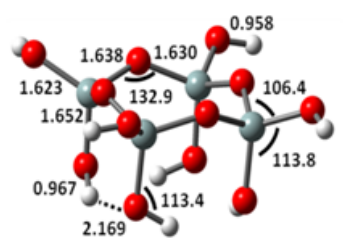

SN4_cyc

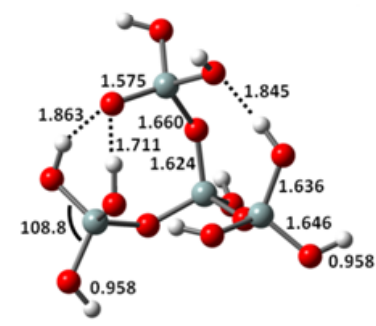

(SN)-2SN,SI

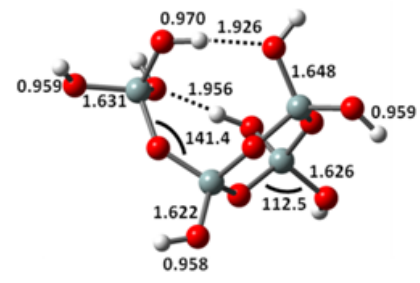

(SN)-SN3_cyc

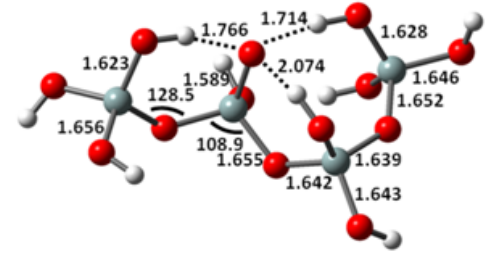

SN2SISN

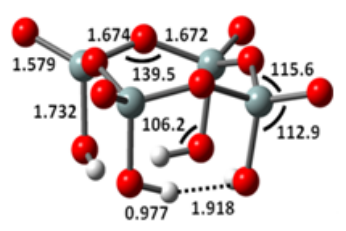

SI4_cyc

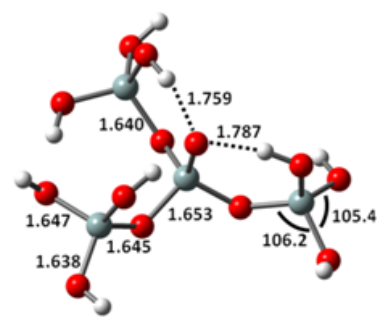

(SI)-3SN

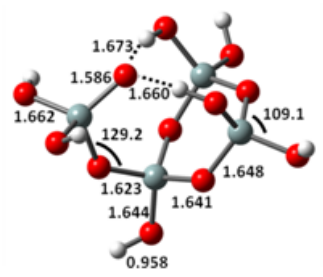

(SI)-SN3_cyc

Figure 4 


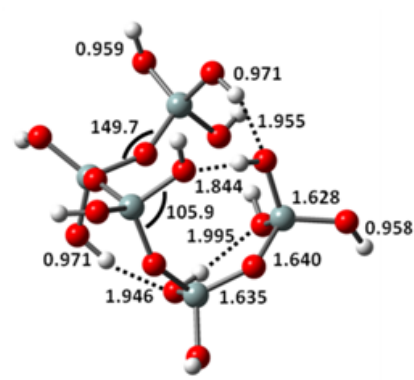

SN5

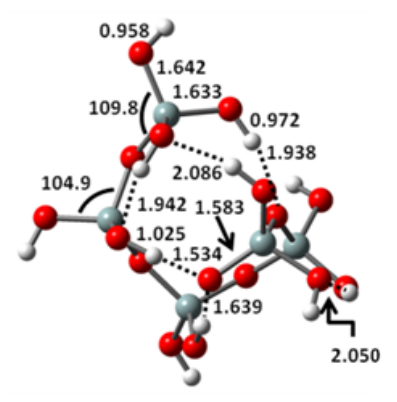

SN4SI

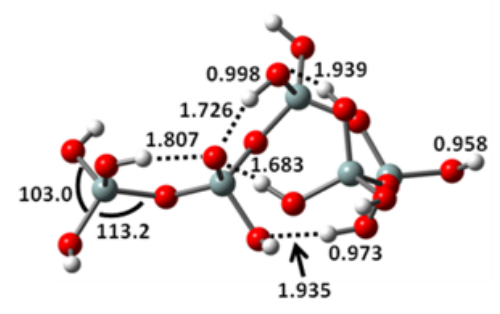

SN3SISN

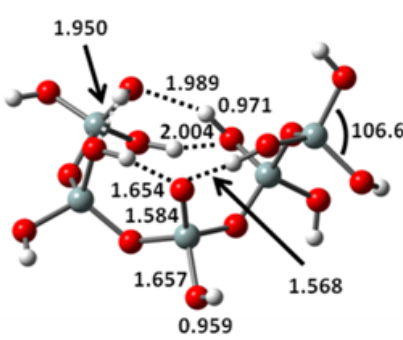

SN2SISN2

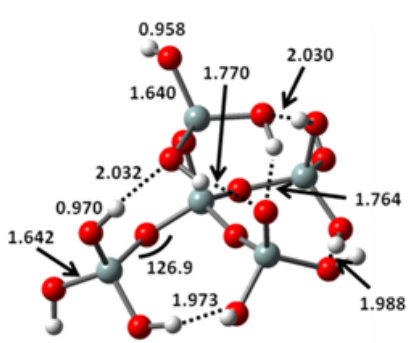

(SN)-3SN,SI

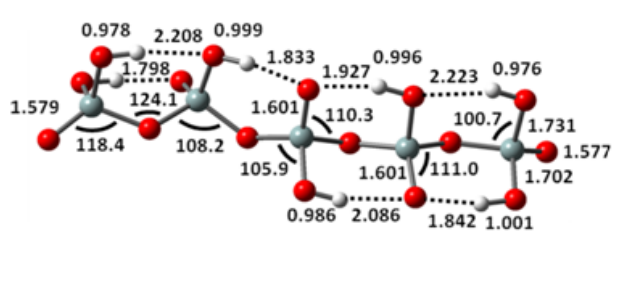

SI5

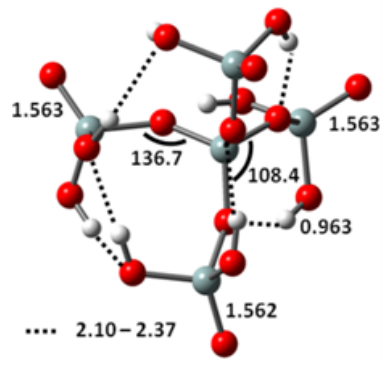

(SN)-4SI

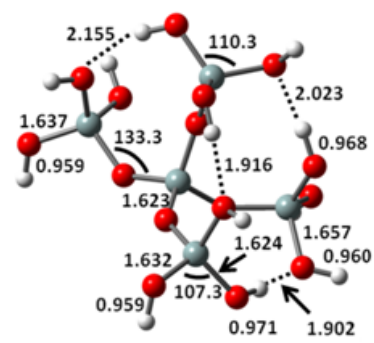

(SN)-4SN

Figure 5 


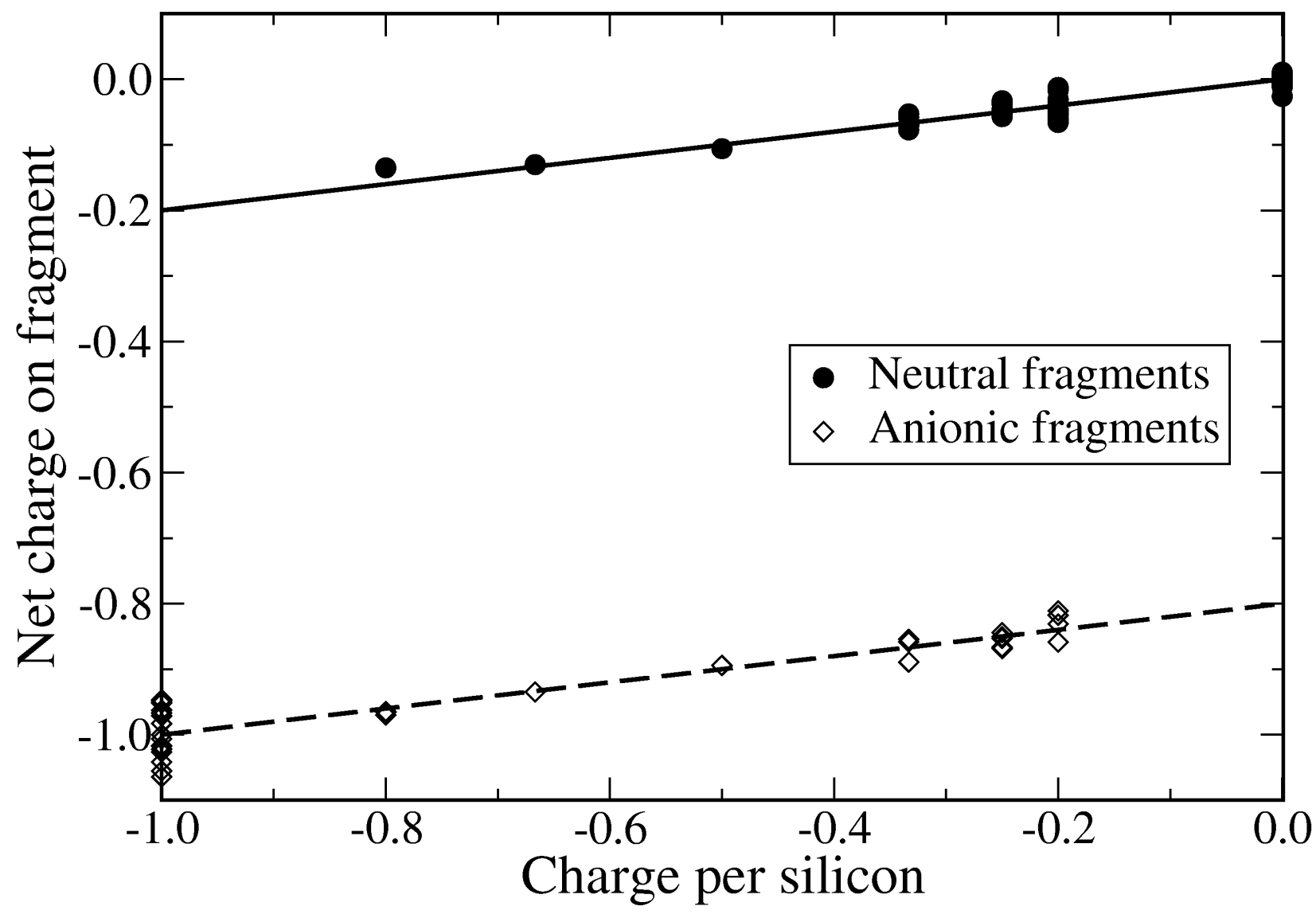

Figure 6 


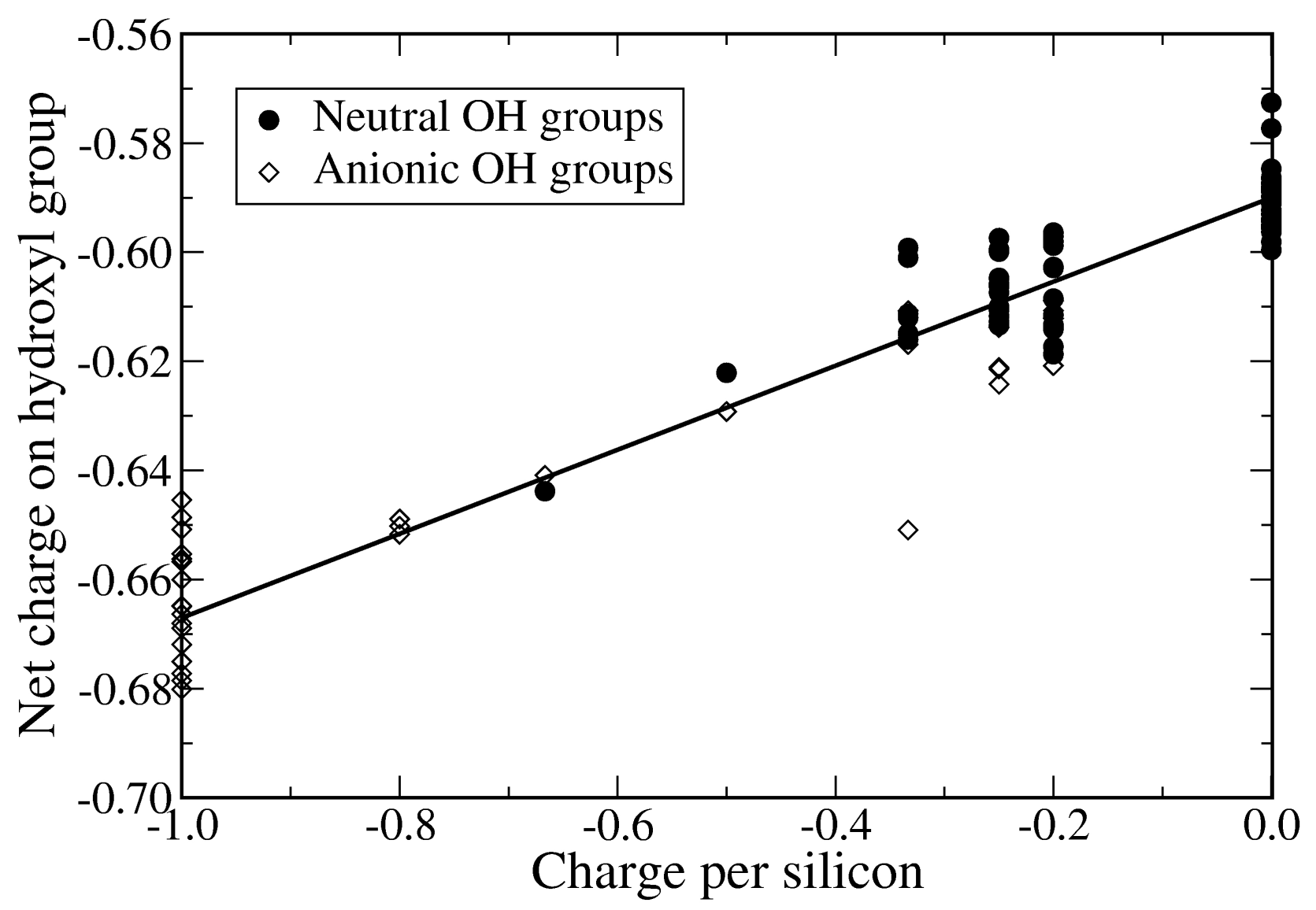

Figure 7 


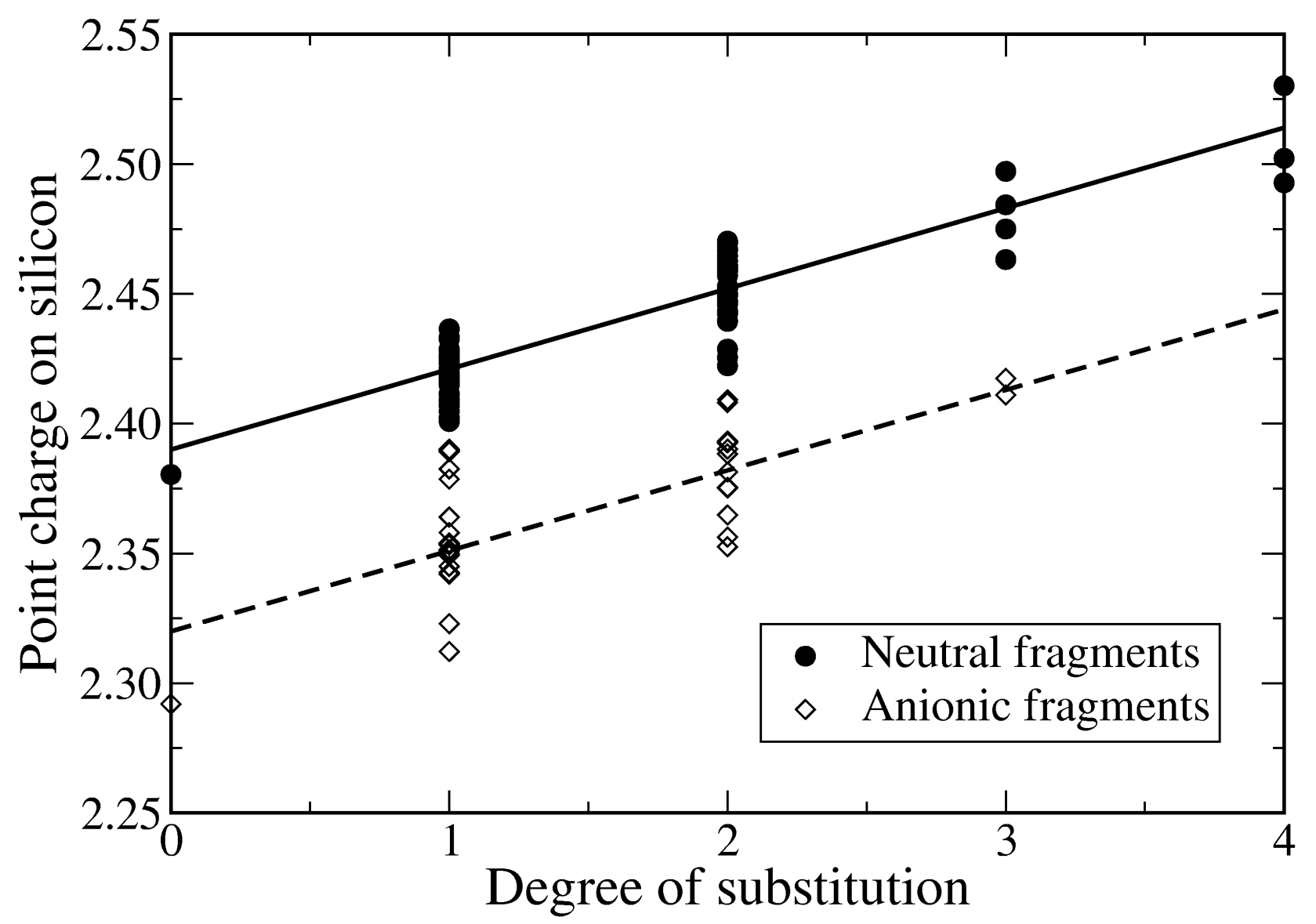

Figure 8 

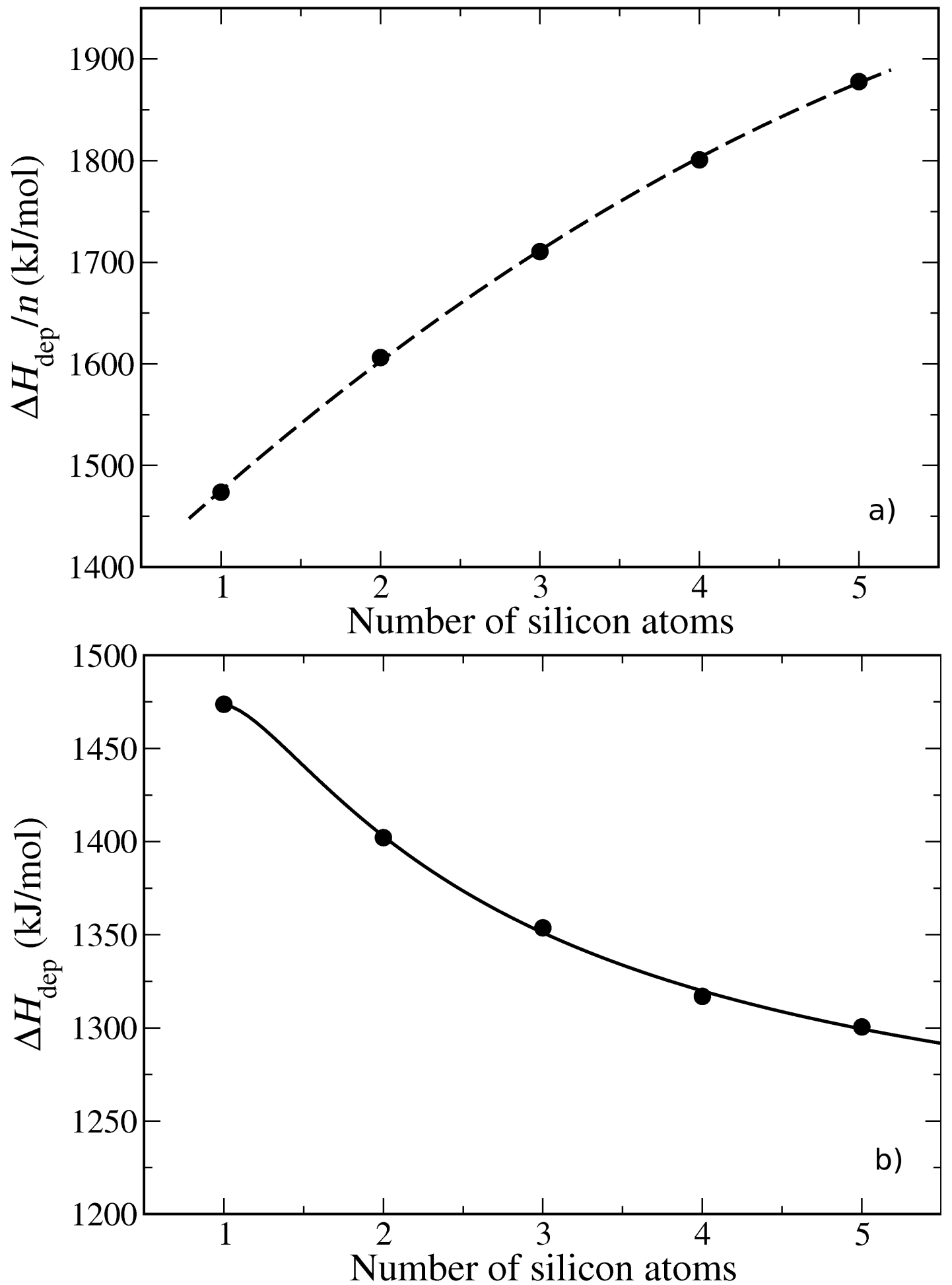

Figure 9 